\title{
Screening the design space for optimized plutonium incineration performance in the thorium-based $I^{2} S-L W R$
}

\author{
D. Kotlyar, G.T. Parks, E. Shwageraus \\ Department of Engineering, University of Cambridge \\ Cambridge CB2 1PZ, United Kingdom
}

\begin{abstract}
Keywords:
$\mathrm{I}^{2} \mathrm{~S}-\mathrm{LWR}$; thorium cycles; plutonium incineration; simulated annealing; WIMS;

PANTHER; BGCore
\end{abstract}

\begin{abstract}
This paper presents an optimization of a thorium-plutonium (Th-Pu) fuel cycle by screening various design options for the Integral Inherently Safe Light Water Reactor ( $\mathrm{I}^{2} \mathrm{~S}-\mathrm{LWR}$ ). The $\mathrm{I}^{2} \mathrm{~S}-\mathrm{LWR}$ is an advanced $2850 \mathrm{MWt}$ integral pressurized water reactor with enhanced safety beyond that of Gen-III+ reactors. The features of this reactor, such as material choice, make it attractive for alternative fuel cycles including the use of thorium. Recently, the feasibility of the Th-Pu cycle was studied and the benefits associated with it were demonstrated. More specifically, the $\mathrm{Pu}$ incineration performance was enhanced by adopting multi-batch (i.e. more than 3-batch) schemes and extended burnup (above $100 \mathrm{MWd} / \mathrm{kg}$ ). The optimized design with the most favorable loading pattern was obtained by applying the Simulated Annealing optimization technique. This paper demonstrates further plausible modifications to the Th-Pu cycle design that may enhance its performance considerably. The paper seeks to identify the contributory factors, such as cladding types, plutonium vectors and initial plutonium loadings, with major impact on the incineration performance. The postirradiation characteristics are also analyzed and suggest that such a cycle may simplify the design and operation of the waste repository.
\end{abstract}




\section{Introduction}

The I'2S-LWR concept (Petrovic, 2014; Salazar and Franceschini, 2014; Salazar et al., 2015) is a large power (i.e. $1 \mathrm{GWe}$ ) pressurized water reactor (PWR) that aims to enhance safety beyond that of Gen-III+ reactors. The project is funded by the US Department of Energy through a Nuclear Energy University Programs (NEUP) Integrated Research Project (IRP). The project is led by the Georgia Institute of Technology and the design team is made up of many universities and industry partners.

The safety features of the design are enhanced by adopting an integral configuration, a fully passive decay heat removal system and the use of new fuel and cladding materials. More specifically, $\mathrm{U}_{3} \mathrm{Si}_{2}$ fuel pellets within advanced $\mathrm{FeCrAl}$ steel or $\mathrm{SiC}$ cladding are proposed.

Recent research (Kotlyar et al., 2017) showed the potential benefits of incorporating the Th-Pu oxide (TOX) fuel cycle in the $\mathrm{I}^{2} \mathrm{~S}-\mathrm{LWR}$ design. Large stockpiles of separated civil plutonium have been accumulated (IAEA, 1998) and pose proliferation and environmental risks. Current experience (IAEA, 2003) of plutonium recycling is mostly limited to mixed oxide U-Pu (MOX) fuel. However, Pu destruction is accompanied by simultaneous generation of $\mathrm{Pu}$ from the U-based matrix when this fuel cycle is employed. The presented TOX fuel cycle was shown to be an attractive candidate for Pu incineration, but would require high discharge burnups, i.e. above 100 $\mathrm{MWd} / \mathrm{kg}$, to be achieved in order to attain the maximum Pu utilization potential. Unlike standard Zr-based alloys, the envisioned cladding materials (e.g. advanced $\mathrm{FeCrAl}$ steel) can withstand longer irradiation periods (Terrani et al., 2012) with much lower degradation of mechanical properties.

The analyses were also complemented by performing optimization studies (Kotlyar and Parks, 2016) that relied on the Simulated Annealing (SA) method (Metropolis and Ulam, 1949; Kirkpatrick et al., 1983). The SA optimization method allowed loading patterns (LPs) that considerably improved $\mathrm{Pu}$ and transuranic elements (TRU) incineration while preserving the required safety margins to be identified. The major issue associated with high $\mathrm{Pu}$ core loadings relates to the moderator temperature coefficient (MTC), which may become positive. Therefore, the SA optimization was applied for different refueling strategies, i.e. 3-, 5- and 7.56-batches. The results confirmed that increasing the number of batches allows the MTC to be kept negative 
and also reduces the power peaking factors. Moreover, the increased number of batches extends the discharge burnup and hence results in deeper $\mathrm{Pu}$ incineration and also improved $\mathrm{Pu}$ utilization.

The optimization studies (Kotlyar and Parks, 2016) were performed for the proposed cladding type (advanced FeCrAl steel), assumed a fixed reactor grade $\mathrm{Pu}$ vector and 16 volume \% loading of $\mathrm{PuO}_{2}$ in the TOX mixture. The optimized design achieved $62 \% \mathrm{Pu}$ incineration and $41 \%$ TRU incineration.

The research reported here seeks to enhance the performance of the TOX cycle even further by identifying various parameters that contribute to the efficient incineration of Pu and TRU. The chosen parameters included different cladding types, reactor grade $\mathrm{Pu}$ vectors, $\mathrm{PuO}_{2}$ volumetric fractions and moderator-to-fuel volume ratios. The SA method was applied to 24 different core designs representing different combinations of the above parameters to identify the most favorable LP (for each design) with respect to cycle length performance.

A second objective was to investigate the post-irradiation fuel characteristics, such as radiotoxicities and decay heat, for the various designs. The design and loading of a repository is governed primarily by the thermal load (Wigeland et al., 2006) and the appropriate temperature limits to ensure adequate performance of the repository. Since different incineration rates can alter the decay heat of the resulting spent nuclear fuel, there is a possibility of improving the utilization of a geological repository of a given size.

The results presented here indicate that more than $75 \%$ of $\mathrm{Pu}$ and $51 \%$ of TRU could be incinerated while preserving the required safety limits. The results also indicate that achieving this high incineration allows the decay heat power and cumulative energy after disposal to be reduced considerably. This would imply that the size of the repository could be reduced or alternatively more waste could be stored in a given space. 


\section{Calculation methodology}

\subsection{Codes}

The optimization analyses of the $I^{2} S-L W R$ thorium-based core designs were performed by linking an external SA implementation (Section 3) that sequentially executed PANTHER (Morrison, 2003). This core physics package is a nodal diffusion code that also includes a thermal-hydraulic module to solve the heat conductionconvection problem. WIMS10 (Newton et al., 2008) was used for lattice data generation by employing a 172-group JEFF3.1-based library. WIMS uses the method of characteristics and/or collision probabilities to obtain the transport solution needed to generate homogenized parameters for each fuel type. WIMS has been extensively verified and is capable of modelling fast and thermal reactor systems, see for example (Lindley et al., 2016).

Decay calculations were performed with the BGCore code to determine the spent fuel radiotoxicity and decay heat following irradiation. BGCore couples the Monte Carlo neutron transport code MCNP with independently developed burnup and thermal-hydraulic modules (Kotlyar et al., 2011). BGCore was verified via a series of code-to-code benchmark exercises for thermal and fast spectrum lattices (Fridman et al., 2008; Bomboni et al., 2010). The ability of BGCore to predict post-irradiation fuel characteristics for standard $\mathrm{UO}_{2}$ and non-conventional fuels was demonstrated in past publications (Fridman et al., 2008; Shwageraus and Hejzlar, 2009).

\subsection{Core management and design}

The various core designs investigated here rely on a multi-batch reloading scheme, implying that the core consists of fresh and burnt assemblies. Previous studies (Kotlyar and Parks, 2016) showed that increasing the number of batches allows the discharge burnup and thus $\mathrm{Pu}$ incineration to be increased. In addition, the increased number of batches eliminates the possibility of the MTC becoming positive. In those studies, various refueling strategies were considered, namely 3-, 5- and 7.56-batch 
schemes. In the current study, it was decided to adopt the 7.56-batch core that assumes 16 fresh assemblies are loaded each cycle.

The assemblies contain burnable poison in the form of integral fuel burnable absorber (IFBA). The ${ }^{10} \mathrm{~B}$ concentration used in the IFBA rods is $0.984 \mathrm{mg} / \mathrm{cm}$. In this research, only a single radial fuel assembly IFBA loading pattern was used to flatten the core power distribution, as illustrated in Fig. 1. Axially, each assembly consists of $3.6576 \mathrm{~m}$ of homogeneous fuel between top and bottom reflectors.

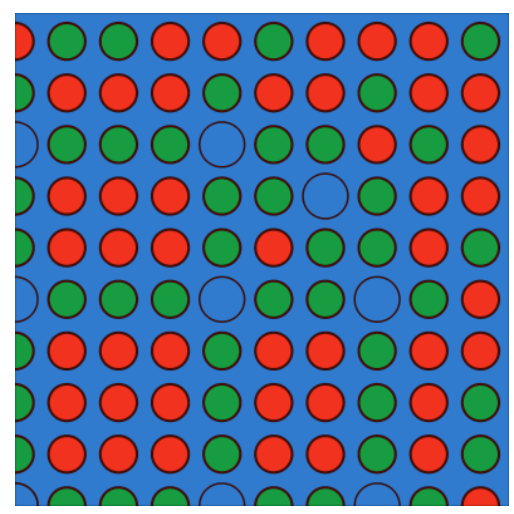

Fig. 1. IFBA (156 rods) loading pattern. The top-right quadrant of the assembly is shown. IFBA rods are indicated by the green circles, blue circles are the guide tubes and red circles are the fuel rods without burnable absorber.

In order to identify how various contributors may affect the performance of the TOX cycle, the following combinations were considered:

- The studied cladding materials included advanced FeCrAl steel and $\mathrm{SiC}$ ceramic composite. The advanced FeCrAl steel cladding is proposed for use in the $\mathrm{I}^{2} \mathrm{~S}$ LWR rather than the current Zr-based materials. This choice is primarily driven by the possibility of enhancing the accident tolerance of the fuel through the deployment of a robust cladding material that can withstand high temperature $\left(>1200^{\circ} \mathrm{C}\right)$ steam-water conditions without experiencing the high oxidation and hydrogen generation rates of $\mathrm{Zr}$-based alloys. However, some of the $\mathrm{Fe}$ and $\mathrm{Cr}$ isotopes have high neutron absorption cross-sections which lead to a significant reactivity penalty. $\mathrm{SiC}$ cladding is also under consideration due to its high temperature strength and slow reaction with steam. Thus, it can also be considered accident tolerant but with a significantly lower neutron absorption 
cross-section than the FeCrAl steel cladding.

- Different volume fractions of $\mathrm{PuO}_{2}$ in the fuel mixture were studied as well. Values of $12 \%, 16 \%$ and $18 \%$ were considered. The densities of $\mathrm{ThO}_{2}$ and $\mathrm{PuO}_{2}$ were set to be $95 \%$ of their theoretical values, which are $9.5 \mathrm{~g} / \mathrm{cm}^{3}$ and 10.89 $\mathrm{g} / \mathrm{cm}^{3}$ respectively. Previous studies (Kotlyar et al., 2017) showed that increasing the $\mathrm{PuO}_{2}$ volume fraction allows higher burnups and therefore deeper incineration to be achieved.

- The performance of three fuel/cladding options $\left(\mathrm{U}_{3} \mathrm{Si}_{2} / \mathrm{FeCrAl}, \mathrm{U}_{3} \mathrm{Si}_{2} / \mathrm{SiC}\right.$ and $\mathrm{UO}_{2} / \mathrm{Zr}$ ) in the $\mathrm{I}^{2} \mathrm{~S}-\mathrm{LWR}$ core was examined previously (Salazar et al., 2015). The use of these options (

- Table 2) would result in a core operating with a slightly different spectrum, enrichment and initial heavy metal (HM) loading, which would therefore reach different discharge burnups. Thus, the reactor-grade $\mathrm{Pu}$ isotopic vector at discharge (after 10 years cooling) would be unique for each option. These different $\mathrm{Pu}$ isotopic vectors (denoted $\mathrm{Pu}-1, \mathrm{Pu}-2$ and $\mathrm{Pu}-3$ ) were all considered in the current study and are presented in Table 3.

- Past studies (Shwageraus et al., 2004) concluded that increasing the hydrogen to heavy metal $(\mathrm{H} / \mathrm{HM})$ ratio will allow higher $\mathrm{Pu}$ and TRU incineration levels to be achieved. Therefore, sensitivity analyses were performed for 2 lattices characterized by different $\mathrm{H} / \mathrm{HM}$ atomic ratios as presented in Table 1 . The analyses for the first lattice (H/HM-1) included a full set of combinations, which resulted in optimization studies of 18 cores: 2 types of cladding $\times 3$ Pu loadings $\times 3$ Pu vectors. Following these analyses it was concluded that a reasonable $\mathrm{PuO}_{2}$ loading would be around $12 \%$. Therefore, for the second lattice $(\mathrm{H} / \mathrm{HM}-2)$ only 6 core designs were studied: 2 types of cladding $\times 3$ $\mathrm{Pu}$ vectors for a single $\mathrm{PuO}_{2}$ loading value of $12 \%$. 
Table 1: Main model parameters.

\begin{tabular}{|l|c|c|}
\hline Parameter & \multicolumn{2}{|c|}{ Value } \\
\hline Core thermal power (MW) & \multicolumn{2}{|c|}{2850} \\
\hline Fuel assembly pitch (cm) & \multicolumn{2}{|c|}{24} \\
\hline Lattice & \multicolumn{2}{|c|}{ FeCrAl or SiC } \\
\hline Control rods per assembly & \multicolumn{2}{|c|}{1.2150} \\
\hline Cladding material & H/HM-1 & H/HM-2 \\
\hline Fuel cell pitch (cm) & 0.4591 & 0.4572 \\
\hline & 0.4097 & 0.3700 \\
\hline Fuel pin outer radius (cm) & 0.0406 & 0.0762 \\
\hline Fuel pellet radius (cm) & 0.5102 & 0.5154 \\
\hline Cladding thickness (cm) & 0.5476 & 0.5527 \\
\hline Guide tube inner radius (cm) & 1.7504 & 2.1590 \\
\hline Guide tube outer radius (cm) & 3.6879 & 4.5488 \\
\hline Moderator-to-fuel volume ratio & 900 & 1030 \\
\hline H/HM atomic ratio & 710 & 715 \\
\hline Average fuel temperature (K) & & \\
\hline Average coolant density (kg/m $\left.{ }^{3}\right)$ & \multicolumn{2}{|c|}{} \\
\hline
\end{tabular}

Table 2: Considered fuel-cladding options in the $\mathrm{I}^{2} \mathrm{~S}-\mathrm{LWR}$ design.

\begin{tabular}{|l|l|l|l|}
\hline & Pu-1 & Pu-2 & Pu-3 \\
\hline Enrichment ( $\left.{ }^{w} \%\right)$ & 4.838 & 4.695 & 4.838 \\
\hline Fuel type & $\mathrm{U}_{3} \mathrm{Si}_{2}$ & $\mathrm{U}_{3} \mathrm{Si}_{2}$ & $\mathrm{UO}_{2}$ \\
\hline Cladding type & $\mathrm{FeCrAl}$ & $\mathrm{SiC}$ & $\mathrm{Zr}$ \\
\hline Discharge burnup (MWd/kgHM) & 42 & 55 & 53 \\
\hline
\end{tabular}

Table 3: Isotopic composition of plutonium vectors.

\begin{tabular}{|l|l|l|l|}
\hline & Pu-1 & Pu-2 & Pu-3 \\
\hline${ }^{238} \mathbf{P u}$ & 2.18 & 3.29 & 2.93 \\
\hline${ }^{239} \mathbf{P u}$ & 63.63 & 54.53 & 55.84 \\
\hline${ }^{240} \mathbf{P u}$ & 21.18 & 25.16 & 24.51 \\
\hline${ }^{241} \mathbf{P u}$ & 8.85 & 9.58 & 9.64 \\
\hline
\end{tabular}




\begin{tabular}{|l|l|l|l|}
\hline${ }^{\mathbf{2 4 2}} \mathbf{P u}$ & 4.15 & 7.44 & 7.08 \\
\hline
\end{tabular}

\section{Loading pattern optimization with Simulated Annealing}

In our recent work (Kotlyar and Parks, 2016), the Simulated Annealing (SA) optimization technique was applied to obtain the most favorable loading pattern with respect to cycle length. A detailed description of the method and the implemented procedure was given previously and thus only a concise summary is presented here. This technique was adopted here for each case (i.e. a combination of cladding type, $\mathrm{Pu}$ vector, $\% \mathrm{PuO}_{2}$ and $\mathrm{H} / \mathrm{HM}$ ratio) with the objective to maximize the cycle length. SA was used to find the minimum value of the multivariate function $F\left(x_{1}, \ldots, x_{n}\right)$ of discrete variables $\left(x_{1}, \ldots, x_{n}\right)$. These variables represent the assemblies' loading pattern within the core and $F$ is the cycle length multiplied by -1 .

First, at each iteration $k$, the SA procedure samples the LP arrangement of the assemblies $x_{1}^{k}, \ldots, x_{n}^{k}$, where $x_{n}^{k}$ is the coordinate of assembly $n$ in the examined configuration. Then, the PANTHER code is executed and the objective function $F^{k}=$ $F\left(x_{1}^{k}, \ldots, x_{n}^{k}\right)$ and maximum power peaking values $g^{k}=g\left(x_{1}^{k}, \ldots, x_{n}^{k}\right)$ are obtained. Penalization of infeasible solutions (with $g^{k}>g_{\max }$ ) is achieved by adding a positive penalty value to the objective function as follows:

$$
\phi\left(x_{1}^{k}, \ldots, x_{n}^{k} ; \mu\right)=F\left(x_{1}^{k}, \ldots, x_{n}^{k}\right)+\mu^{k} \times\left(g^{k}\right)^{\gamma(\alpha)}
$$

where the power of the constraint violation term $\gamma$ is itself violation-dependent. Here, a simple threshold relation was adopted:

$$
\begin{aligned}
& \gamma(\alpha)= \begin{cases}1, & \alpha \leq 0.1 \\
2, & \alpha>0.1\end{cases} \\
& \alpha=g-g_{\max }
\end{aligned}
$$

It should be noted that for negative values of $\alpha$, the corresponding penalty term is zero. The parameter $\mu$ is a positive penalty parameter. In addition, since the penalty application process is iterative, a scheme to update $\mu$, which also includes an upper bound to prevent problems becoming ill-conditioned, was implemented:

$$
\mu^{k+1}=\min \left(c \mu^{k}, \mu_{\max }\right)
$$

where $c>1$ and $k$ represents the iteration counter. The values of the various parameters used are given in Table 4. 
The following procedure was used to implement the SA algorithm:

1) Set $k=1, T_{0}, c, \mu^{0}, g_{\max }$

2) Sample an initial LP arrangement of the various assemblies $x_{1}^{k}, \ldots, x_{n}^{k}$ and calculate $\phi^{k}$.

3) Randomly select a new configuration $x_{1}^{k+1}, \ldots, x_{n}^{k+1}$ and calculate $\phi^{k+1}$. Only a binary swap of fuel assemblies is allowed at each new random selection.

4)

a. If the current objective function $\phi^{k+1} \leq \phi^{k}$, then accept the new LP.

b. Otherwise, if $\phi^{k+1}>\phi^{k}$, accept the less preferable solution/LP with annealing probability:

$$
p=\exp \left(-\frac{k}{T_{0}}\left(\phi^{k+1}-\phi^{k}\right)\right)
$$

c. If the new LP was accepted, update $\left(x_{1}^{k}, \ldots, x_{n}^{k}\right)=\left(x_{1}^{k+1}, \ldots, x_{n}^{k+1}\right)$, $\phi^{k}=\phi^{k+1}$, the index $k=k+1$ and the penalty $\mu^{k+1}$ according to Eq.3.

5) Go to step (3).

The term $\frac{k}{T_{0}}$ in Eq. (4) is simply a continuous cooling annealing parameter that gradually reduces the probability of accepting a less preferable solution as $k$ increases.

\section{SA optimization results}

Optimization exercises were performed with SA for each of the considered cases separately. More specifically, the TOX cores were loaded with fuel that has one of each of the following parameters:

- $\mathrm{PuO}_{2}$ loadings: $12 \%, 16 \%$ or $18 \%$ by volume in the fuel mixture

- Initial Pu isotopic vectors: $\mathrm{Pu}-1, \mathrm{Pu}-2$ or Pu-3 (Table 3)

- Cladding types: FeCrAl or $\mathrm{SiC}$

- H/HM ratios: 3.69 or 4.55 (Table 1)

As mentioned, the objective function chosen for optimization was the cycle length. An upper limit was set to the maximum cycle total power peaking. The parameter values used in the optimizations are specified in Table 4. 
Table 4: Optimization parameters.

\begin{tabular}{|l|l|}
\hline Parameter & Value \\
\hline$T_{0}$ & 300 \\
\hline$c$ & 1.02 \\
\hline$\mu^{0}$ & 1.02 \\
\hline$\mu_{\max }$ & 60 \\
\hline Maximum allowed power peaking $\left(g_{\max }\right)$ & 1.80 \\
\hline
\end{tabular}

For each of the cases, 1500 different LPs were examined with full 3D neutronic and thermal-hydraulic calculations performed by PANTHER until equilibrium was achieved. Fig. 2 and Fig. 3 present arbitrary selected examples of the results for $12 \%$ $\mathrm{PuO}_{2}$ in the TOX mixture and for 2 different initial $\mathrm{Pu}$ vectors (Pu-1 and $\left.\mathrm{Pu}-2\right)$. The figures depict the values of the cycle length versus the associated total power peaking factor. In these figures, the filled green circles represent all the LPs evaluated and the red triangles denote the LPs accepted during the optimization. The optimal LPs found - those with the longest cycle lengths that satisfied the maximum cycle total power peaking constraint - are denoted by the purple squares. The complete set of all optimal LPs examined in the current work is shown in Fig. 4 through Fig. 6.

Fig. 2 and Fig. 3 illustrate the ability of SA search to accept "uphill" moves and, because of the penalty function approach used to handle constraints, to accept solutions for which the constraints are violated. 


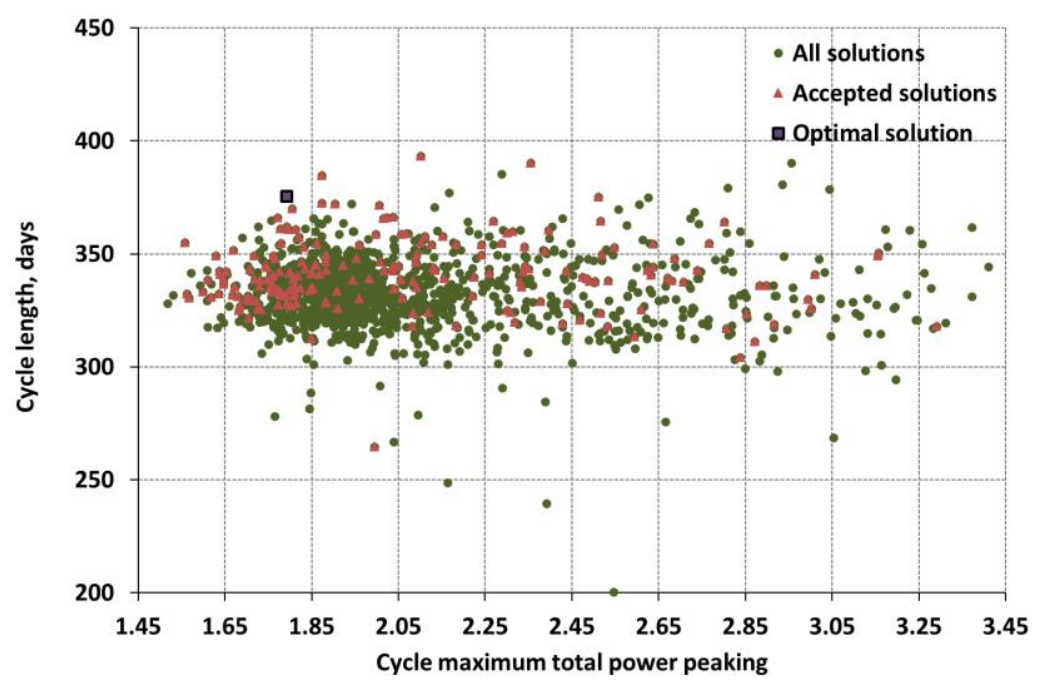

a. FeCrAl cladding

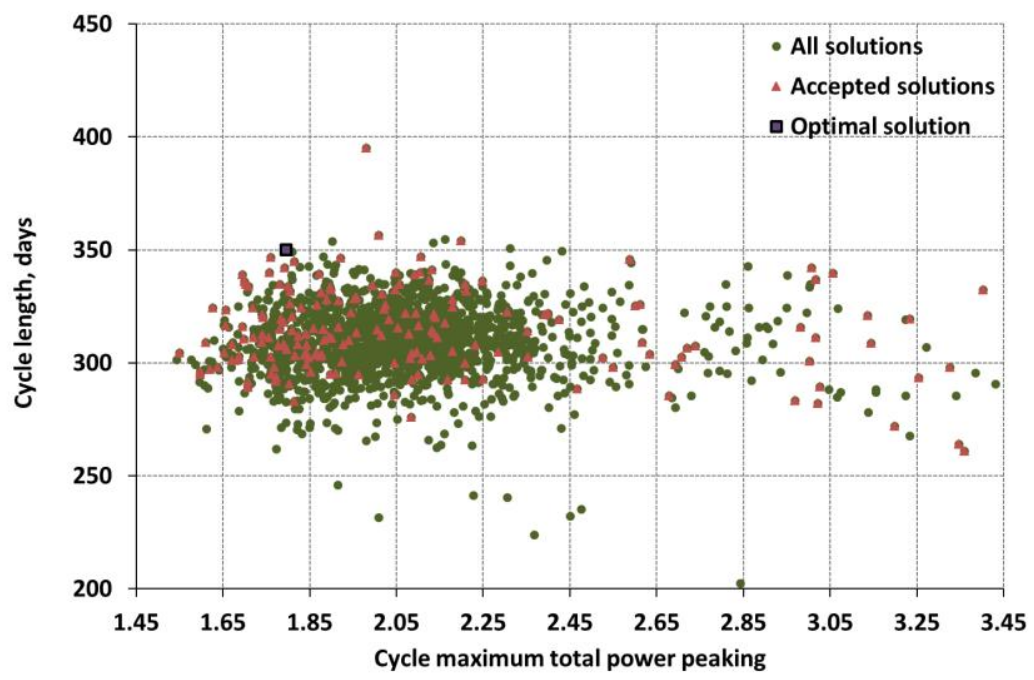

b. SiC cladding

Fig. 2. Cycle length vs. cycle maximum power peaking factor for $12 \% \mathrm{PuO}_{2}$ with the $\mathrm{Pu}-1$ vector. 


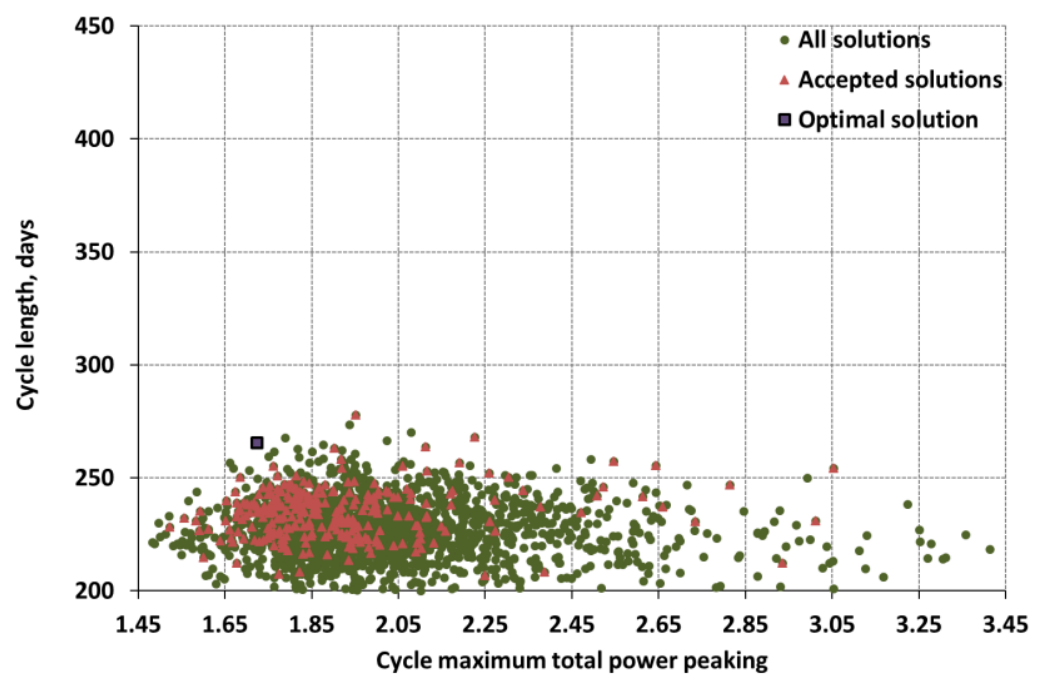

a. FeCrAl cladding

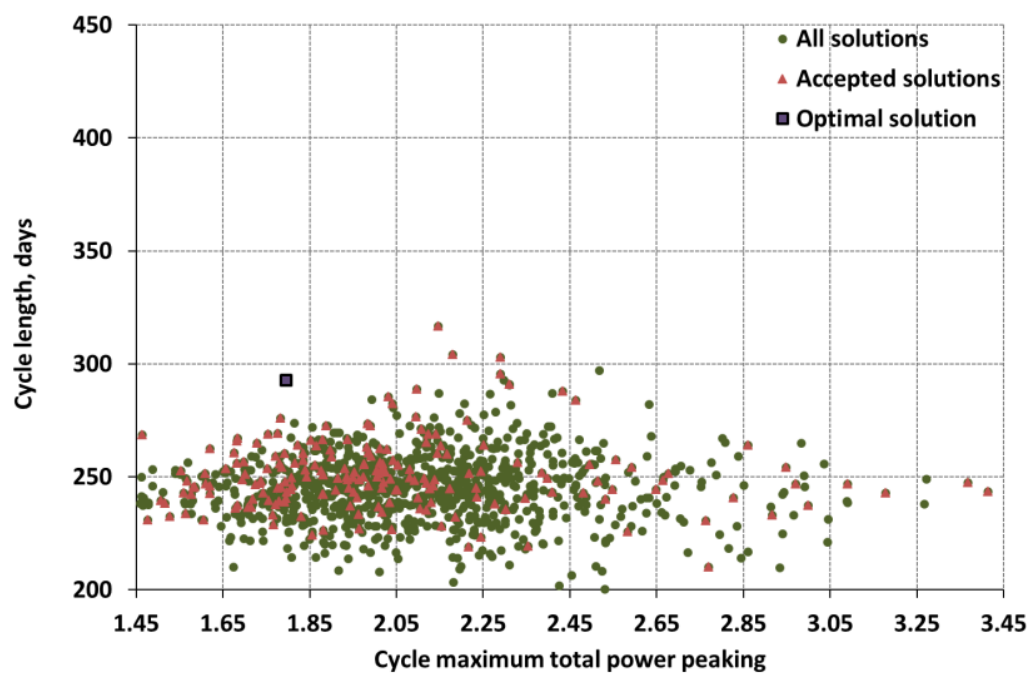

b. SiC cladding

Fig. 3. Cycle length vs. cycle maximum power peaking factor for $12 \% \mathrm{PuO}_{2}$ with the

$\mathrm{Pu}-2$ vector. 

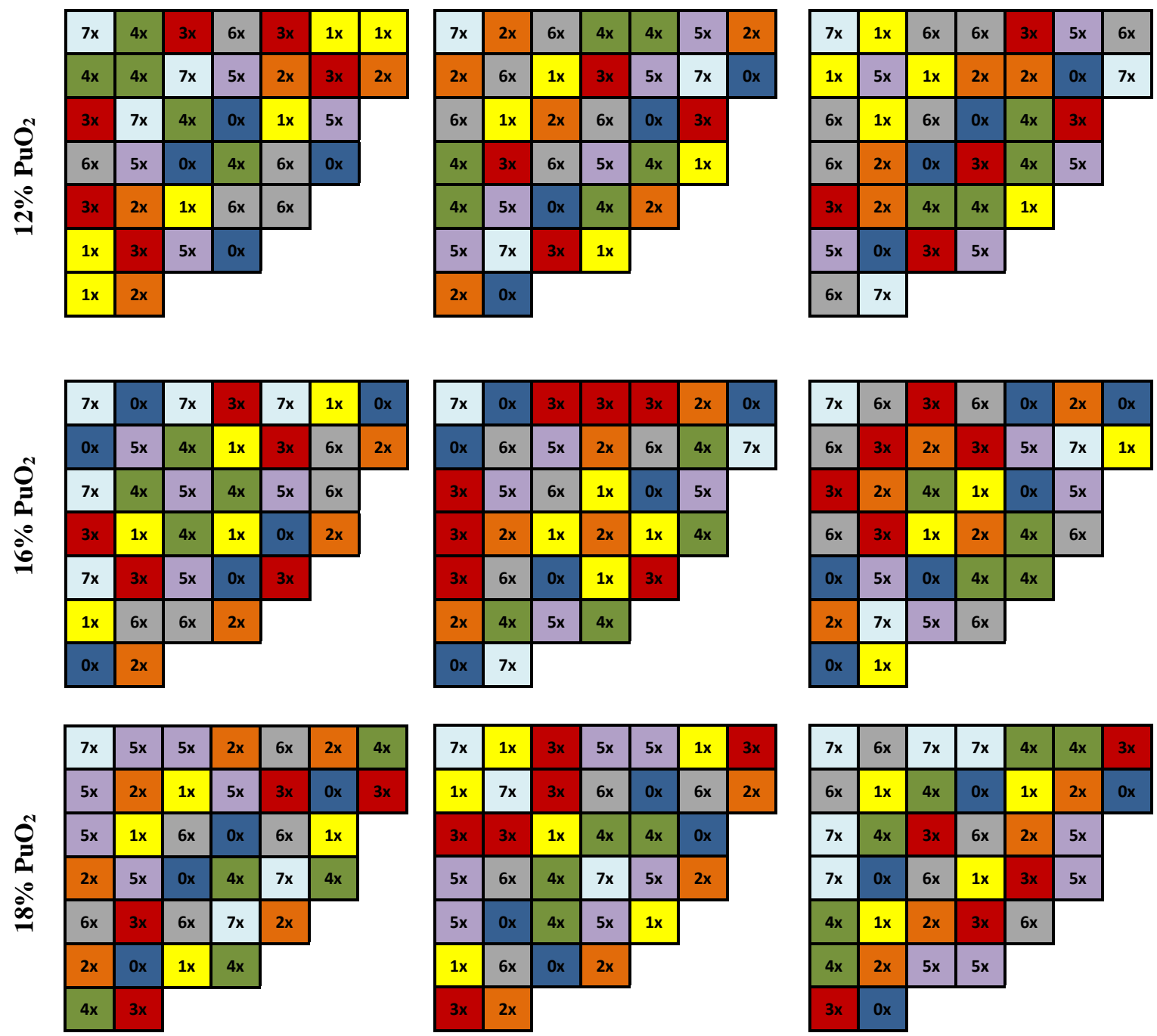

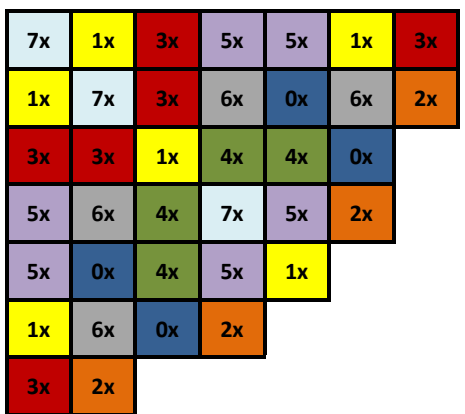

Pu-2

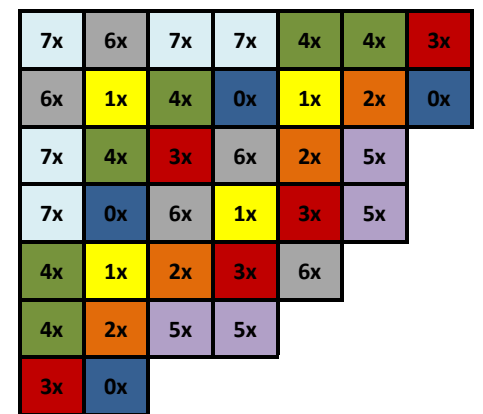

Pu-3

Fig. 4. Optimized equilibrium cycle core LPs for H/HM-1 and FeCrAl options. The labels ' $i \times$ ' denote the number of core residence cycles. 

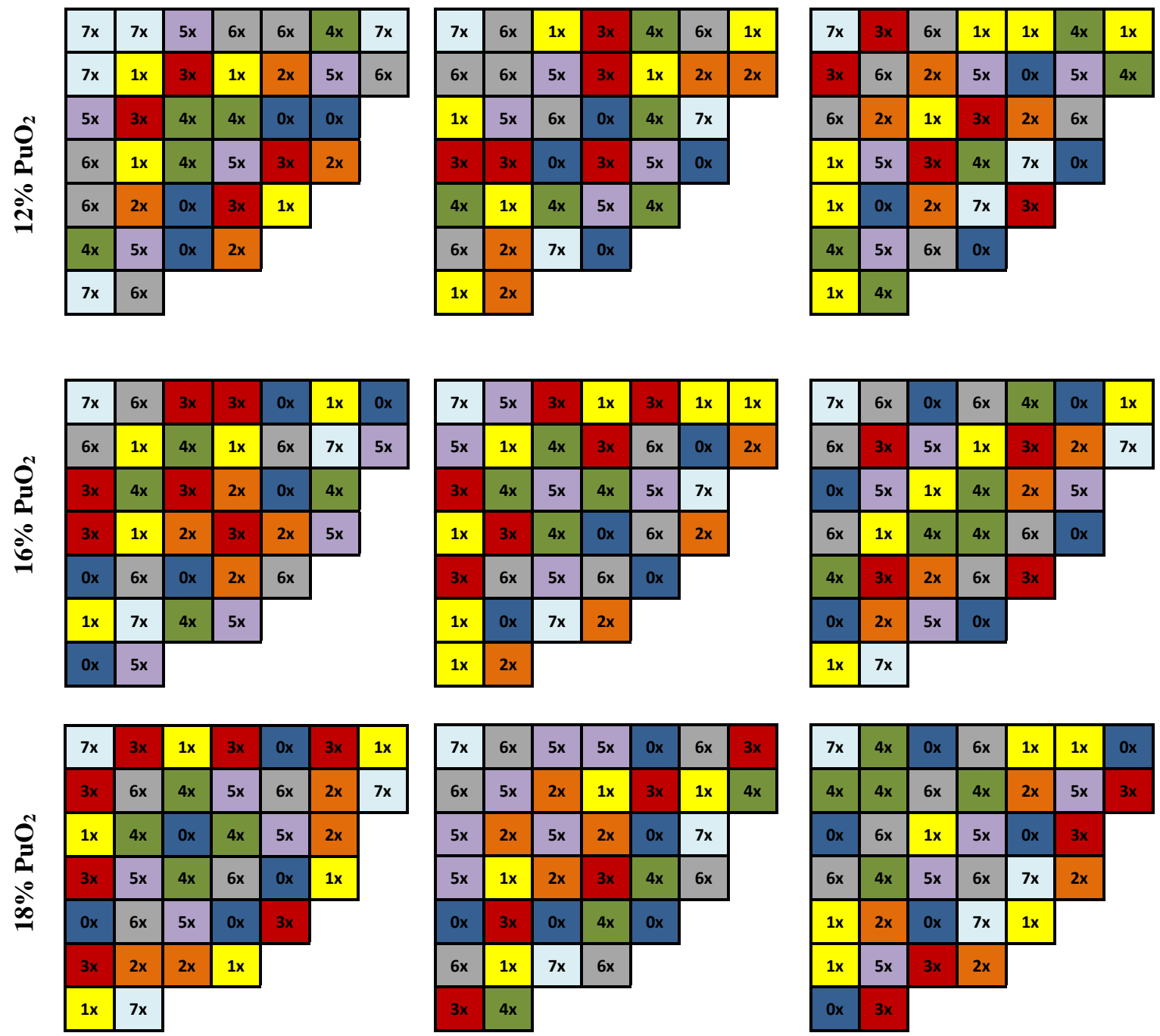

Pu-1

Pu-2

Pu-3

Fig. 5. Optimized equilibrium cycle core LPs for H/HM-1 and SiC options. The labels ' $i \times$ ' denote the number of core residence cycles. 

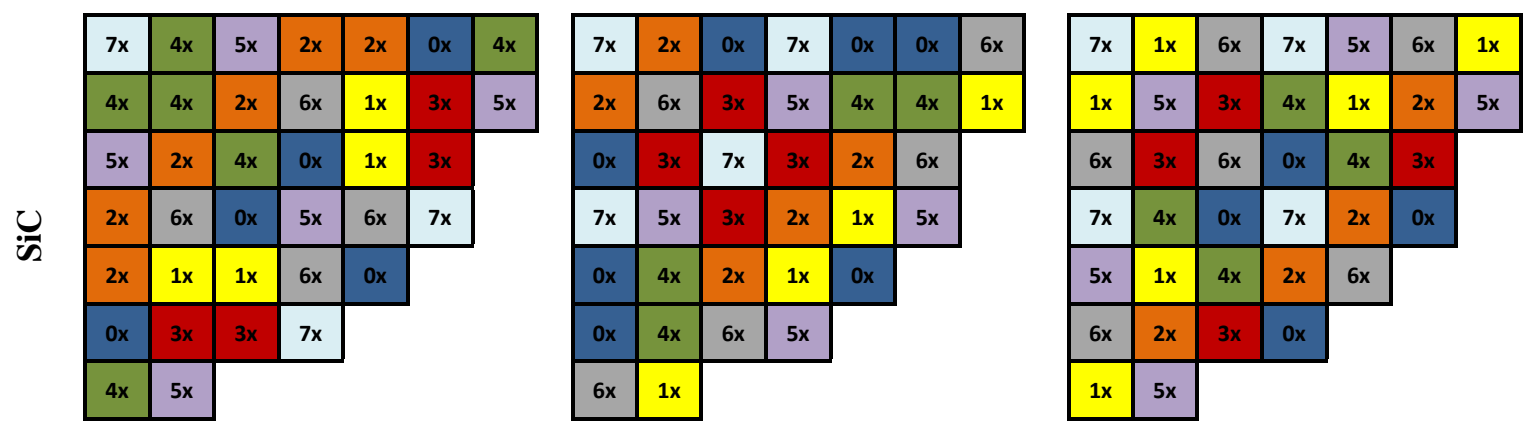

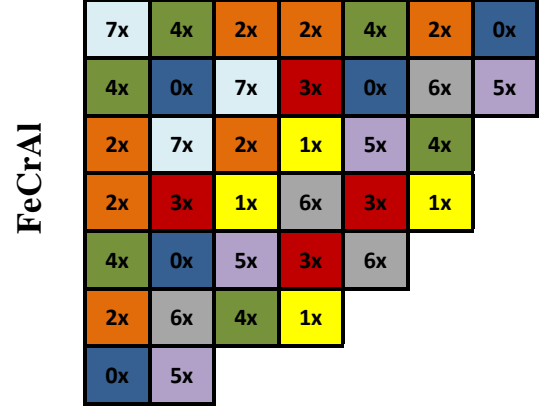

Pu-1

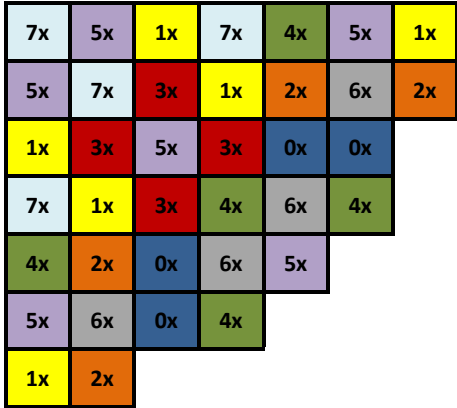

Pu-2

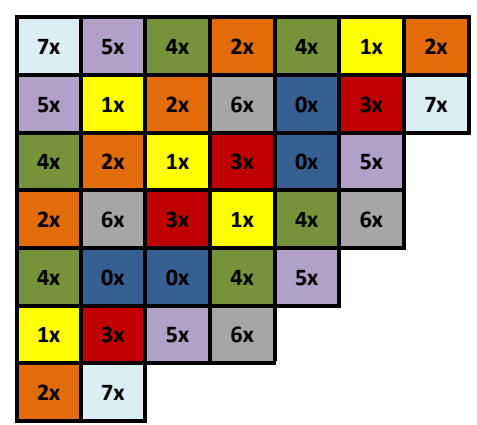

Pu-3

Fig. 6. Optimized equilibrium cycle core LPs for $\mathrm{H} / \mathrm{HM}-2$ and $12 \% \mathrm{PuO}_{2}$. The labels ' $i \times$ ' denote the number of core residence cycles. 
Fig. 7 through Fig. 10 compare the performance of the various designs for H/HM-1. These results correspond to the LPs shown in Fig. 4 and Fig. 5. Each figure presents the results for different $\mathrm{Pu}$ vectors $(\mathrm{Pu}-1, \mathrm{Pu}-2$ and $\mathrm{Pu}-3)$, various $\mathrm{PuO}_{2}$ loadings (12\%: blue, 16\%: red, 18\%: grey) and different cladding types (FeCrAl: full column; SiC: dashed column). The results presented in Fig. 7 through Fig. 10 lead to the following observations:

- Contributors that increase the cycle length (Fig. 7) and hence burnup (Fig. 8):

- Increased Pu volume fraction in the mixture.

- Higher fissile content in the Pu vector (e.g. Pu-1).

- Lower parasitic absorption in the cladding: FeCrAl has an approximately $1 \%$ higher absorption rate compared to the $\mathrm{SiC}$ cladding.

- Plutonium (Fig. 9) and TRU (Fig. 10) incineration performance:

- The results again indicate that there is a strong incentive to increase the initial Pu volume fraction since it enhances $\mathrm{Pu}$ and TRU incineration. In the case with $\mathrm{FeCrAl}$ cladding and the $\mathrm{Pu}-2$ vector, for example, 57.2\% and $64.1 \%$ of the loaded plutonium is incinerated for $12 \%$ and $18 \%$ of loaded $\mathrm{PuO}_{2}$ in the mixture respectively. The designs with the $\mathrm{Pu}-1$ vector show considerably higher incineration rates. These attractive incineration rates are achieved due to the higher fissile content of the $\mathrm{Pu}-$ 1 vector that allows higher fuel burnups to be reached. It must be pointed out that loading more $\mathrm{PuO}_{2}$ in this case $(\mathrm{Pu}-1)$ doesn't help higher incineration rates to be achieved; this is due to the lower build-up rate of ${ }^{233} \mathrm{U}$ from ${ }^{232} \mathrm{Th}$.

- It must be pointed out that the nodal discharge burnup obtained from the $3 \mathrm{D}$ core analyses were used to extract the actinide concentrations at the discharge point.

- It seems that the most promising combination is $\mathrm{SiC}$ cladding, the $\mathrm{Pu}-1$ vector with a loading fraction of 12 volume $\%$ of $\mathrm{PuO}_{2}$ in the $(\mathrm{Pu}-\mathrm{Th}) \mathrm{O}_{2}$ mixture. This design achieves a reasonable cycle length of $\sim 376$ days and discharge burnup of $116 \mathrm{MWd} / \mathrm{kg}$. Moreover, this combination allows more than $75 \%$ of the initial $\mathrm{Pu}$ and $51 \%$ of TRU loaded into the core to be incinerated. In this work, only 3 discrete $\% \mathrm{PuO}_{2}$ values were considered and therefore the optimized number may not be exactly $12 \%$. However, additional sensitivity studies suggest that it 
is indeed close to $12 \%$.

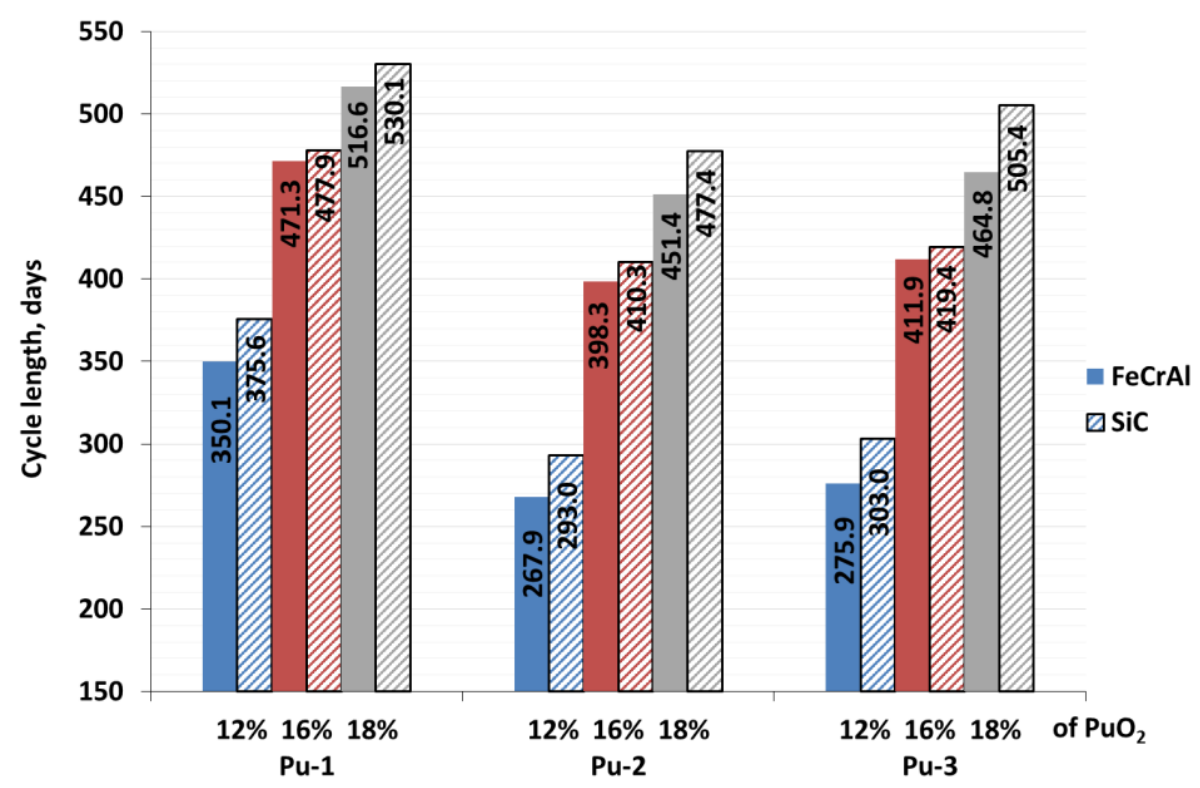

Fig. 7. Cycle length values for various cladding materials, $\mathrm{Pu}$ vectors and $\% \mathrm{PuO}_{2}$ for H/HM-1.

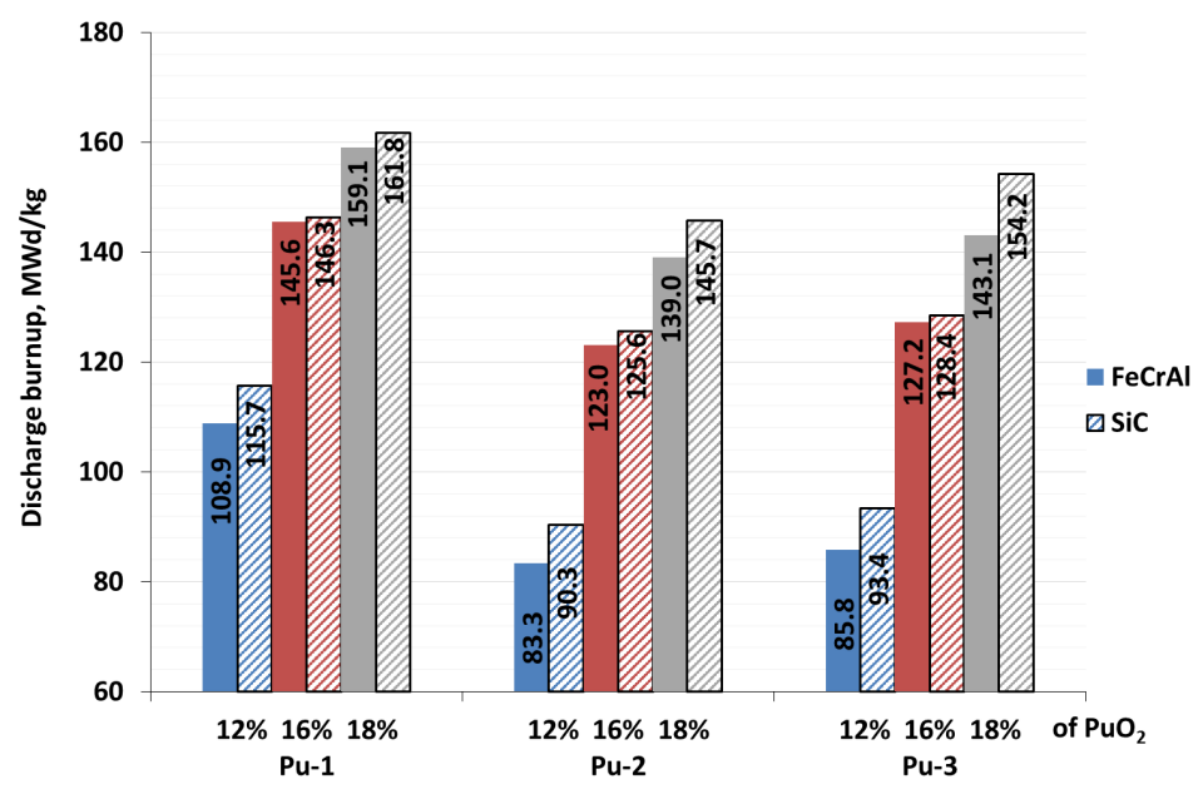

Fig. 8. Discharge burnups for various cladding materials, $\mathrm{Pu}$ vectors and $\% \mathrm{PuO}_{2}$ for H/HM-1. 


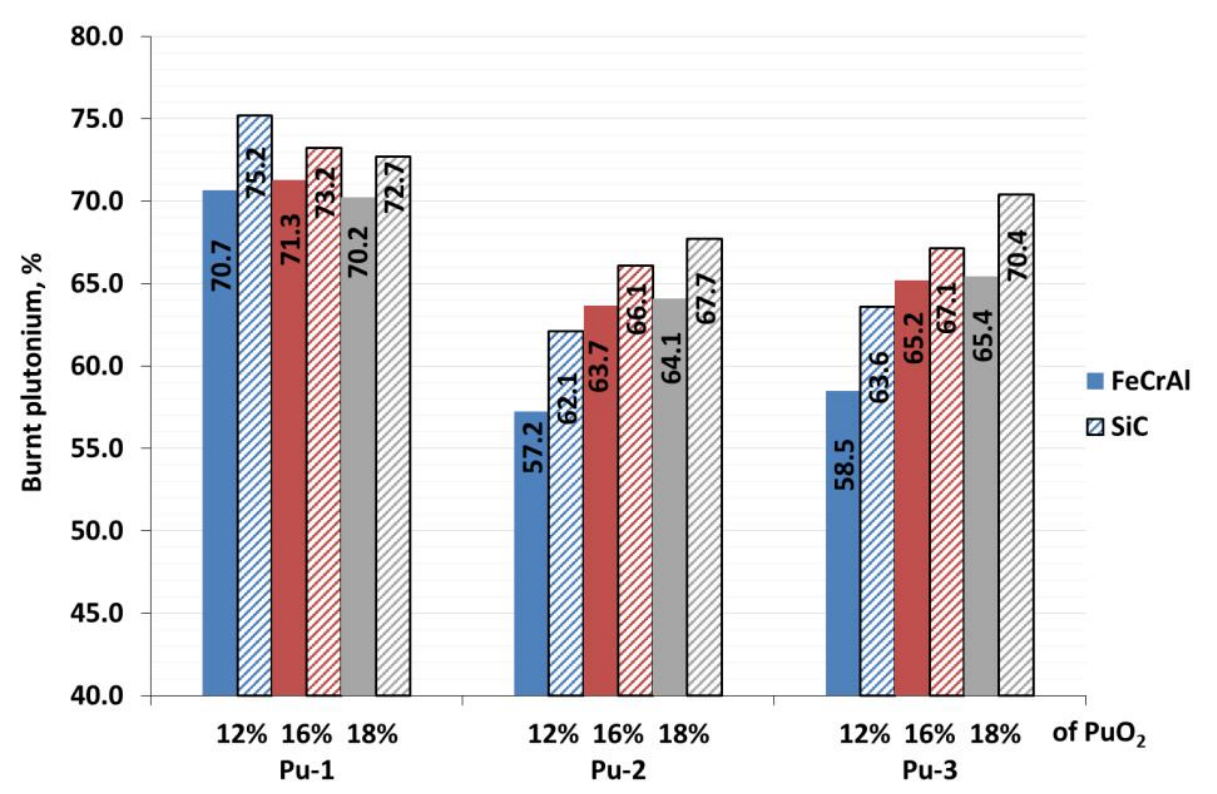

Fig. 9. Burnt- $\mathrm{Pu}(\%)$ for various cladding materials, $\mathrm{Pu}$-vectors and $\% \mathrm{PuO}_{2}$ for H/HM-1.

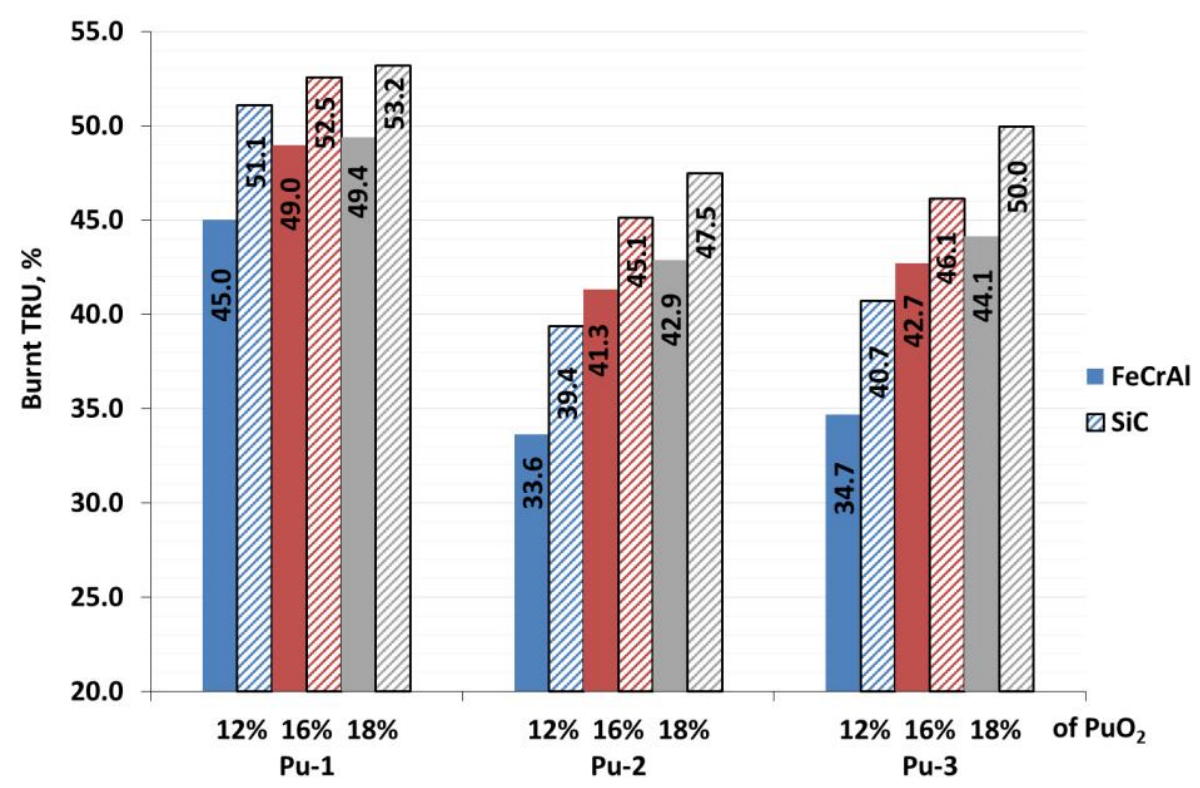

Fig. 10. Burnt-TRU (\%) for various cladding materials, $\mathrm{Pu}$-vectors and $\% \mathrm{PuO}_{2}$ for H/HM-1. 
Fig. 11 through Fig. 14 compare the performance of various designs for the 2 different $\mathrm{H} / \mathrm{HM}$ lattice designs for a single $\mathrm{PuO}_{2}$ loadings of $12 \%$. In the $\mathrm{H} / \mathrm{HM}-2$ designs, the dimensions of the fuel pin were reduced while the pitch was fixed (Table 1). These results correspond to the LPs shown in Fig. 6.

Fig. 11 shows that the cycle lengths obtained are considerably shorter since the core contains less mass of fuel, although the burnup is similar (Fig. 12). The designs with more thermal lattices (H/HM-2) achieve roughly the same Pu (Fig. 13) and TRU (Fig. 14) incineration rates. However, in these designs, the fuel power density is increased and hence the centerline fuel temperature is considerably higher (by about $800{ }^{\circ} \mathrm{C}$ ) than in the H/HM-1 designs. These results are somewhat contradictive of previous research (Shwageraus et al., 2004), which showed that incineration of $\mathrm{Pu}$ improves with increasing the H/HM ratio for the values chosen here. However, those studies were performed on a unit cell configuration, whereas the results presented here were obtained from full core analysis. Moreover, the LPs identified by the SA optimization algorithm were different for the various cases examined. The main conclusion to be drawn here is that increasing $\mathrm{H} / \mathrm{HM}$ has a negligible effect on the incineration of $\mathrm{Pu}$, but a considerable one in terms of thermal-hydraulic performance.

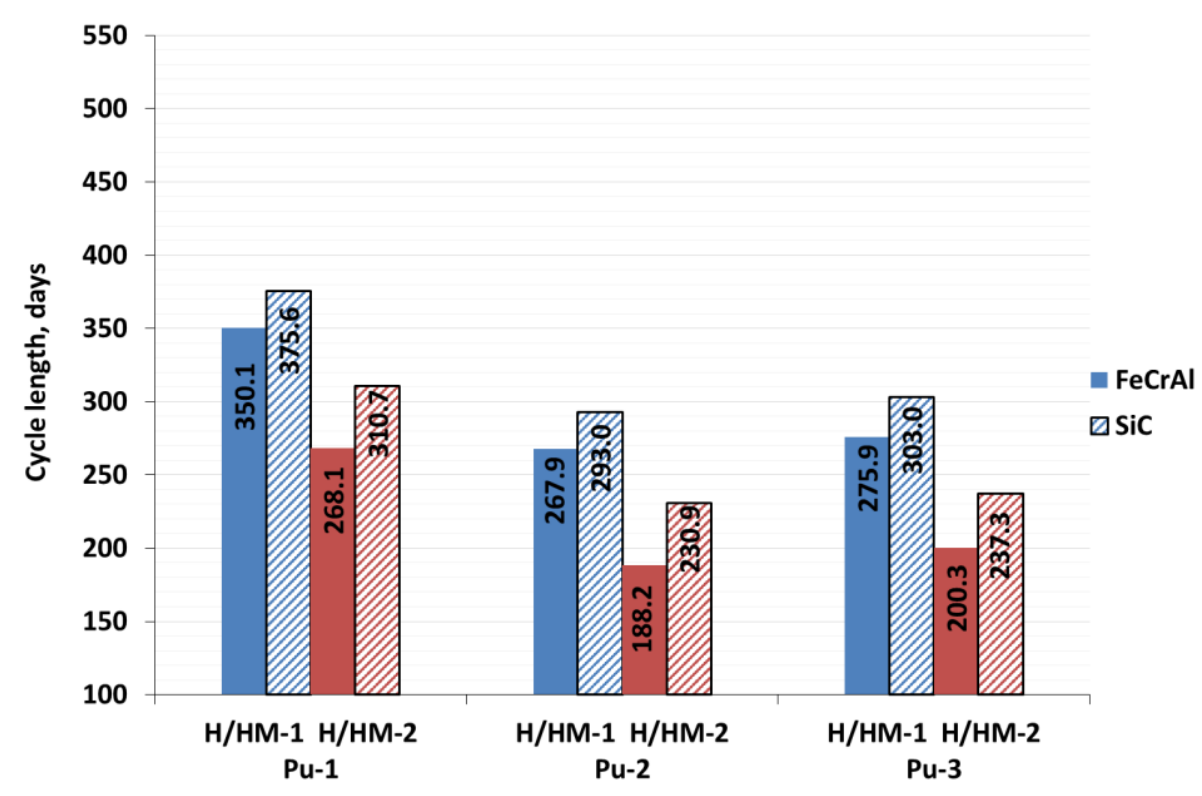

Fig. 11. Cycle length comparison between H/HM-1 and H/HM-2 designs. 


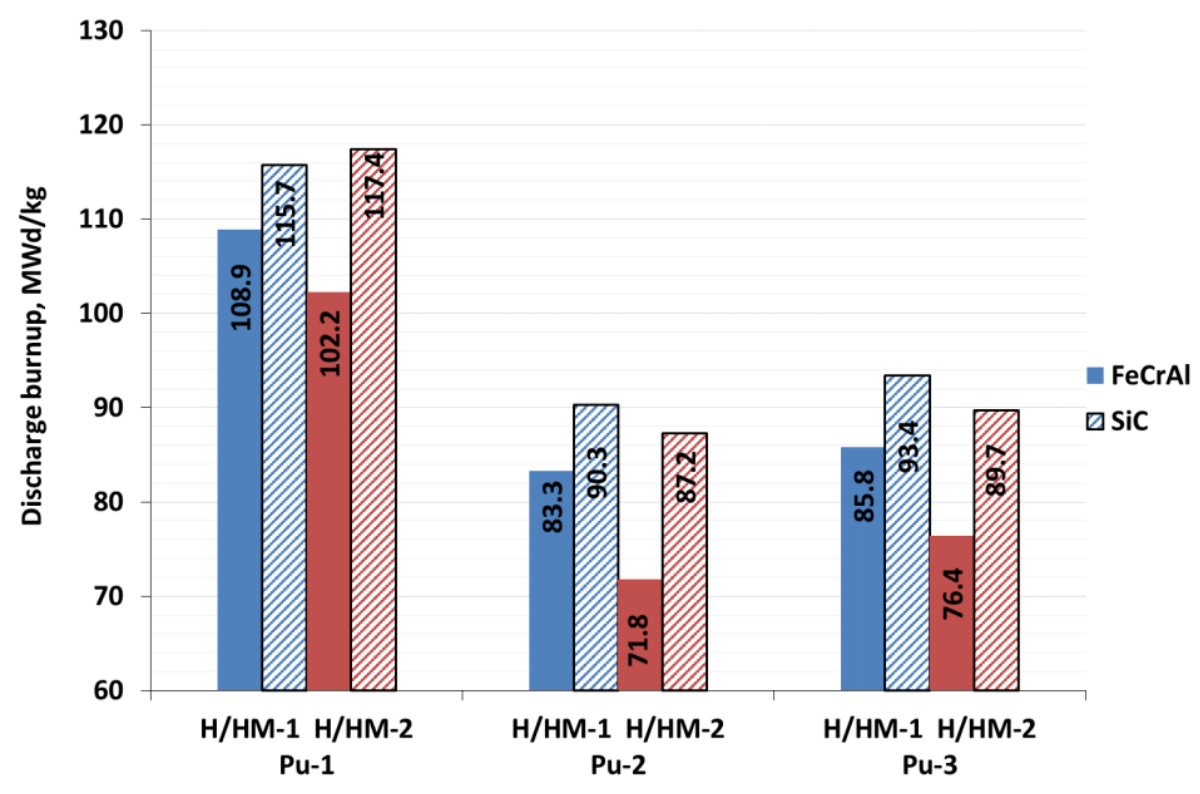

Fig. 12. Discharge burnup comparison between H/HM-1 and H/HM-2 designs.

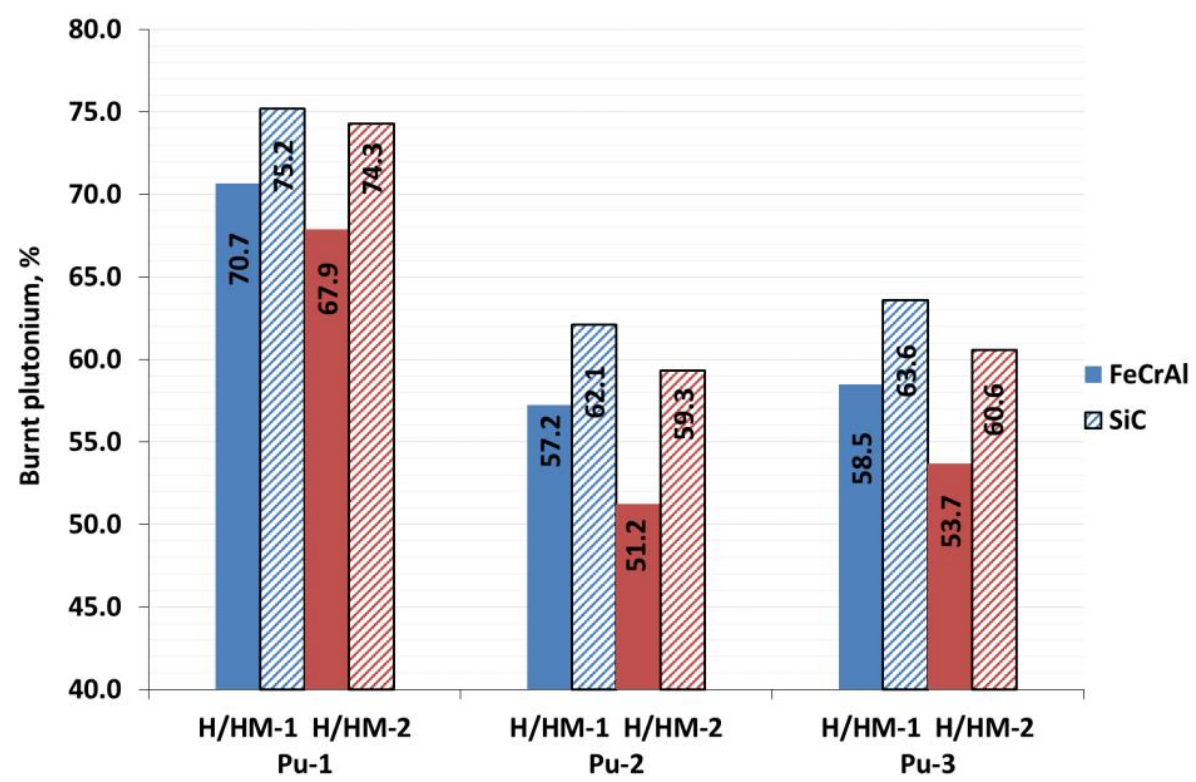

Fig. 13. Incinerated Pu comparison between H/HM-1 and H/HM-2 designs. 


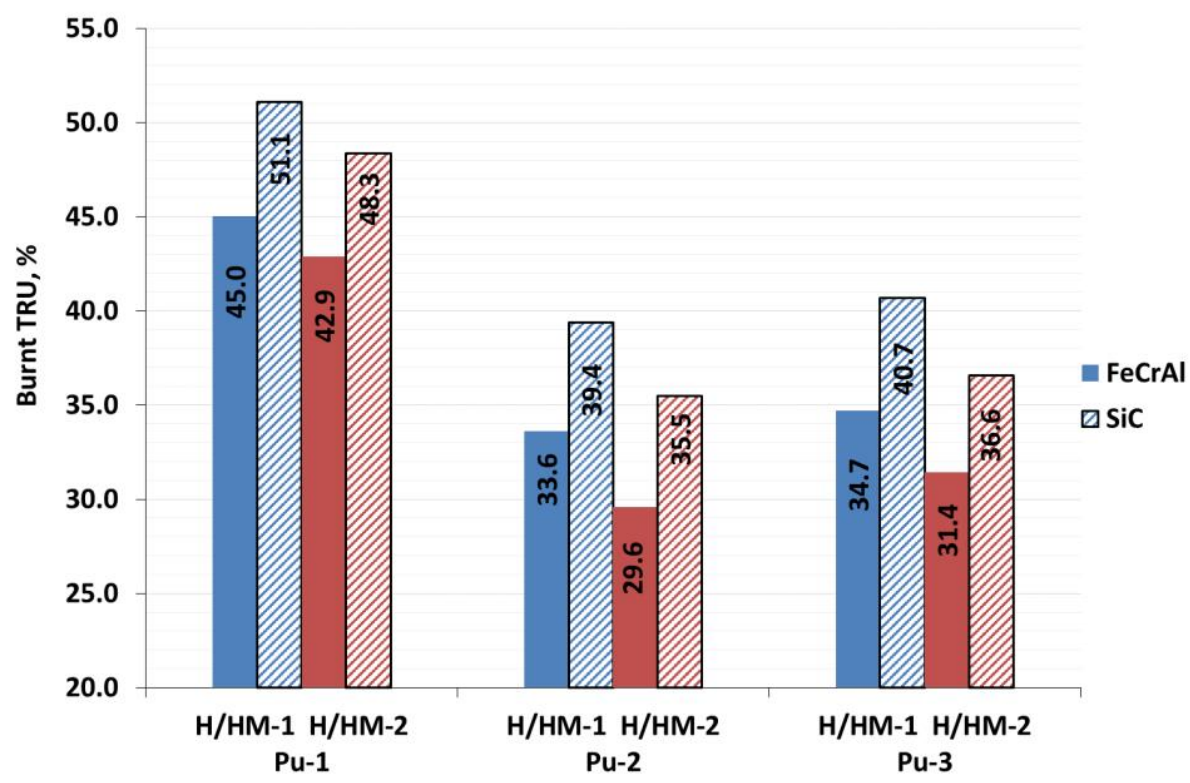

Fig. 14. Incinerated TRU comparison between H/HM-1 and H/HM-2 designs. 


\section{Post-irradiation fuel characteristics results}

This section presents the decay analysis results for the different incineration strategies considered in the current research. The first strategy is the open fuel cycle, where $\mathrm{U}_{3} \mathrm{Si}_{2}$ fuel is irradiated up to about $42 \mathrm{MWd} / \mathrm{kg}$ in the $\mathrm{I}^{2} \mathrm{~S}-\mathrm{LWR}$ core and then disposed directly of as high-level waste (Fig. 15a). The second strategy is to extract $\mathrm{Pu}$ from the previous waste stream and mix it with thorium to create a TOX fuel, i.e. $(\mathrm{Pu}, \mathrm{Th}) \mathrm{O}_{2}$, which is then re-introduced into the $\mathrm{I}^{2} \mathrm{~S}-\mathrm{LWR}$ core (Fig. 15b). For consistency, all the calculations in this stage were performed with BGCore, which was used to extract the fuel composition at the discharge burnups provided by PANTHER for the different designs considered here. Then, BGCore was also used to perform postirradiation characteristics calculations for the different options. Radiotoxicity analysis and decay heat calculation results for the different forms of spent nuclear fuel (SNF) are presented in Sections 5.1 and 5.2 respectively.

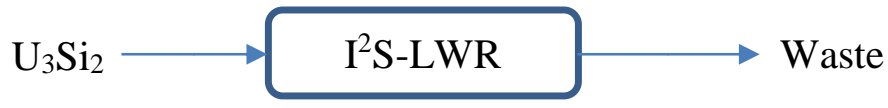

a. Open $\mathrm{U}_{3} \mathrm{Si}_{2}$ fuel cycle

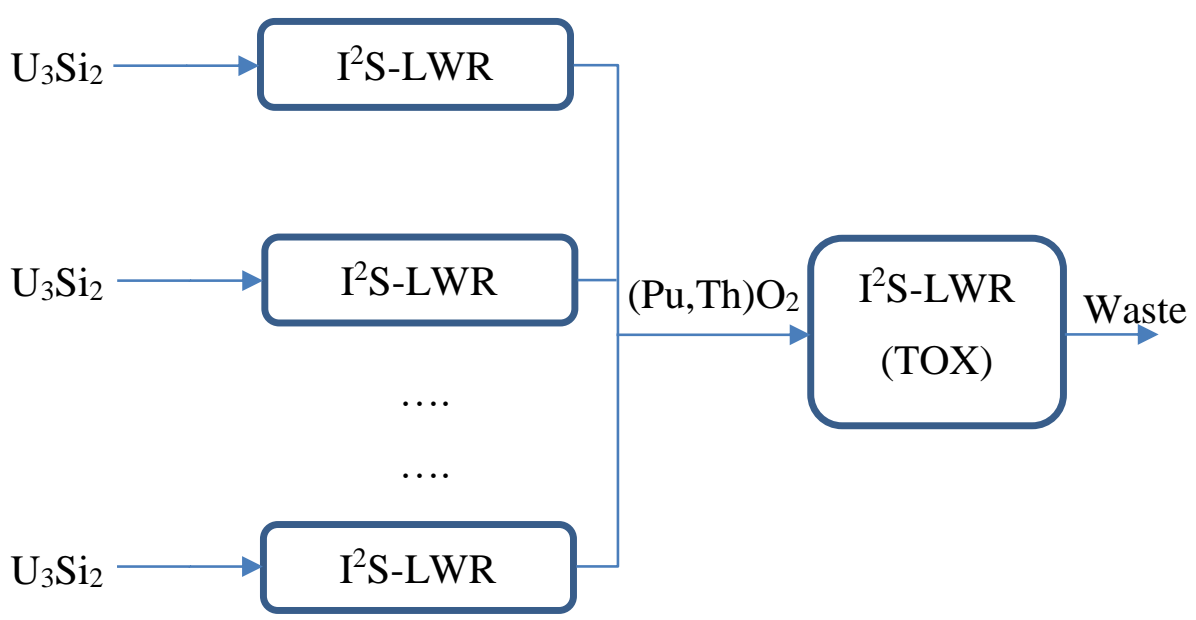

b. 2-tier $\mathrm{U}_{3} \mathrm{Si}_{2}$-TOX fuel cycle

Fig. 15. Fuel cycles scenarios. 
The decay calculations for the first scenario were performed for the composition (designated here as $M_{U_{3} S i_{2}}$ ) obtained at the discharge burnup of $42 \mathrm{MWd} / \mathrm{kg}$. In the second scenario, the decay calculations were performed for the waste stream $\left(M_{\text {waste }}\right)$ that includes the streams of both $\mathrm{Pu}$-generating and $\mathrm{Pu}$-burning cores:

$$
M_{\text {waste }}=N\left(\%_{\mathrm{PuO}_{2}}\right) \times M_{U_{3} \mathrm{Si}_{2}}{ }^{*}+M_{\mathrm{TOX}}
$$

where $M_{U_{3} S_{2}}{ }^{*}$ is the composition of $M_{U_{3} S i_{2}}$ excluding Pu nuclides, and $N\left(\%_{P u O_{2}}\right)$ is the required number of $\mathrm{U}_{3} \mathrm{Si}_{2}$ cores to fuel a single TOX core (Table 5) and thus depends on the loading $\left(\%_{\mathrm{PuO}_{2}}\right)$ of $\mathrm{PuO}_{2}$ in the TOX mixture. Lastly, $M_{T O X}$ represents the irradiated TOX spent fuel inventory, which is unique for each examined case (i.e. $\mathrm{Pu}$ vector, loading and cladding type).

Table 5: Mass balance for $\mathrm{U}_{3} \mathrm{Si}_{2}$ and TOX cores.

\begin{tabular}{|l|l|}
\hline \multicolumn{2}{|l|}{$\mathrm{HM}$ core loading (t) } \\
\hline $\mathrm{U}_{3} \mathrm{Si}_{2}$ & 82 \\
\hline TOX & 67 \\
\hline Number of $\mathrm{U}_{3} \mathrm{Si}_{2}$ cores to fuel a single TOX core \\
\hline With $12 \%$ of $\mathrm{PuO}_{2}$ & 4.68 \\
\hline With $16 \%$ of $\mathrm{PuO}_{2}$ & 6.21 \\
\hline With $18 \%$ of $\mathrm{PuO}_{2}$ & 6.98 \\
\hline
\end{tabular}




\subsection{Radiotoxicity characteristics}

The potential biological hazard of a nuclear waste is measured by either ingested or inhaled radiotoxicities in Sieverts (Sv). The ingested/inhaled radiotoxicity for a given isotope is determined by the activity $(\mathrm{Bq})$ multiplied by the isotope effective dose for ingestion or inhalation coefficients ( $\mathrm{Sv} / \mathrm{Bq}$ units), which are isotope-dependent. These coefficients account for radiation type and tissue weighting factors, metabolic and biokinetic information of an adult based on ICRP 72 report (ICRP, 1995). Typically, ingestion radiotoxicity is considered to be more significant than inhalation radiotoxicity for long-term disposal. This is because the greatest biological hazard to humans occurs when the isotope is absorbed in nearby ground water and eventually enters the food chain. Therefore, all the radiotoxicity values used in this work are calculated as ingested radiotoxicity to maintain consistency and expressed in relative terms, i.e. divided by the ingested radiotoxicity of the equivalent freshly mined natural uranium.

The radiotoxicity curves versus time after discharge for $\mathrm{U}_{3} \mathrm{Si}_{2}$ and $\mathrm{Pu}$ incinerated to different levels in TOX fuel are shown in Fig. 16. Note that radiotoxicity curves presented in Fig. 16 through Fig. 18 include the actinides as well as fission products. Fig. 16 shows that the radiotoxicity for TOX is notably lower than that of $\mathrm{U}_{3} \mathrm{Si}_{2}$ in the $10-10^{5}$ years range. After this period, the radiotoxicity of TOX SNF becomes greater than that of $\mathrm{U}_{3} \mathrm{Si}_{2}$ due to the build-up of highly radiotoxic ${ }^{229} \mathrm{Th}$ from alpha decay of

${ }^{233} \mathrm{U}$. Moreover, deeper Pu incineration further reduces the radiotoxicities in the $10-10^{5}$ years range. For example, after $10^{4}$ years, the radiotoxicity of the TOX waste stream, for which the $\mathrm{Pu}$ is burnt to $30 \%, 50 \%$ or $75 \%$ levels, is lower by a factor of $1.5,2.1$ and 3.9 respectively when compared to the radiotoxicity from the $\mathrm{U}_{3} \mathrm{Si}_{2}$ waste stream. The $\mathrm{Pu}$ vectors used are not identified in Fig. 16 because it was found that radiotoxicity curves are to all intents and purposes identical and depend only on the amount of $\mathrm{Pu}$ burnt in the second tier. Fig. 17 and Fig. 18 show the radiotoxicity of TOX wastes for different $\% \mathrm{PuO}_{2}$ loadings and $\mathrm{Pu}$ vectors respectively. The important thing to note is that for identical amounts of burnt plutonium, the behavior of radiotoxicity as a function of time is very similar. However, in reality different cases offer different Pu incineration rates, as was shown in Fig. 9 and Fig. 13. 


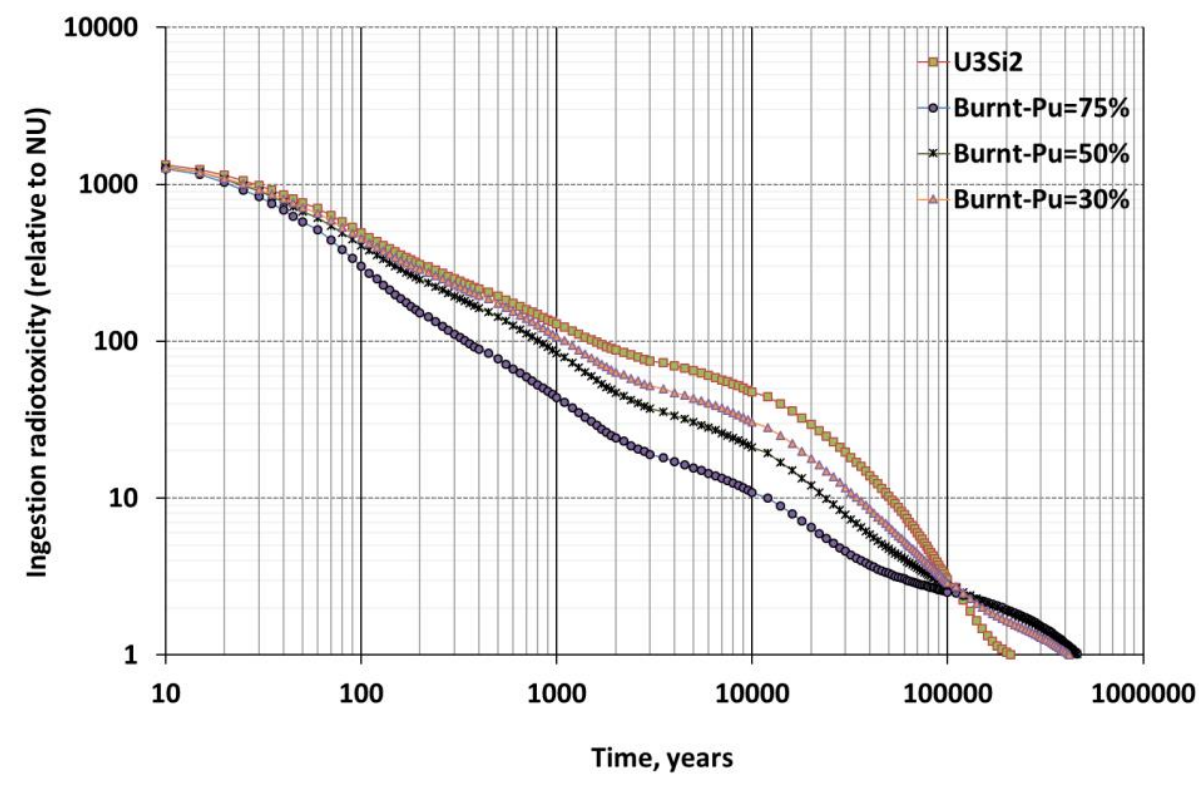

Fig. 16. Relative ingestion radiotoxicity of TOX (incinerated to different levels) and $\mathrm{U}_{3} \mathrm{Si}_{2} \mathrm{SNF}$.

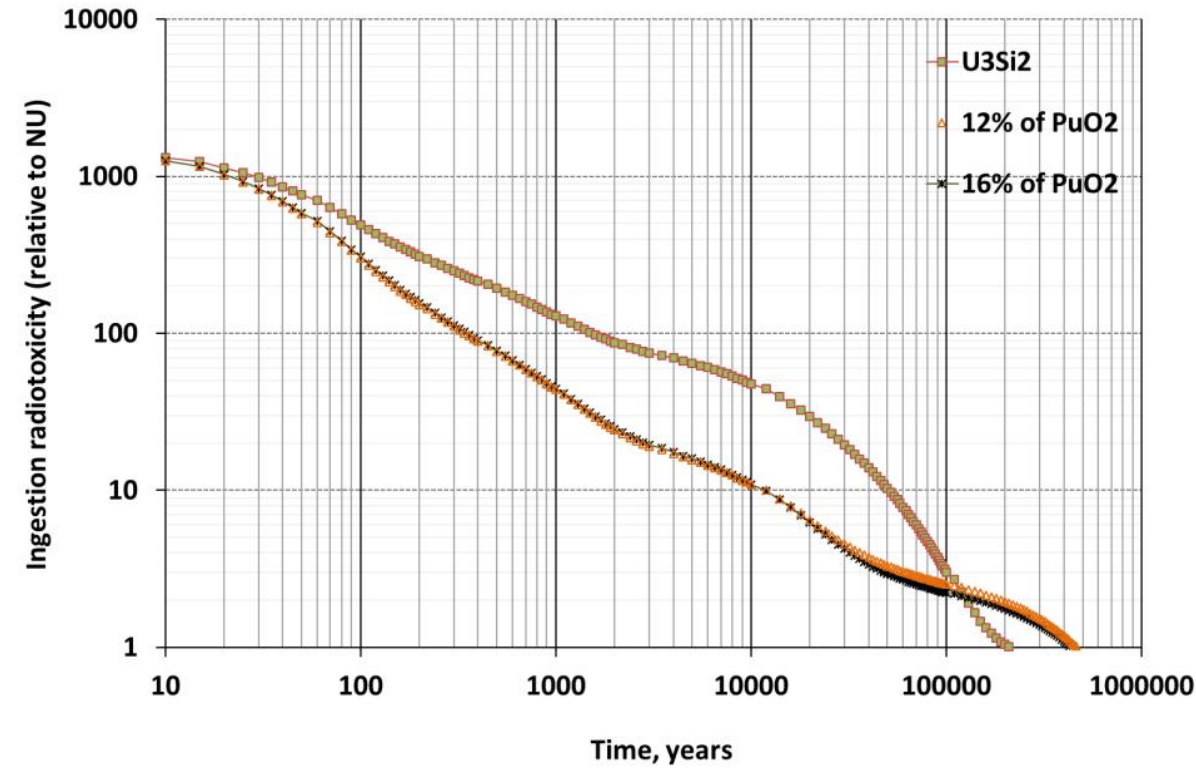

Fig. 17. Relative ingestion radiotoxicity of TOX with different $\mathrm{PuO}_{2}$ volumetric loadings and $\mathrm{U}_{3} \mathrm{Si}_{2} \mathrm{SNF}$. 


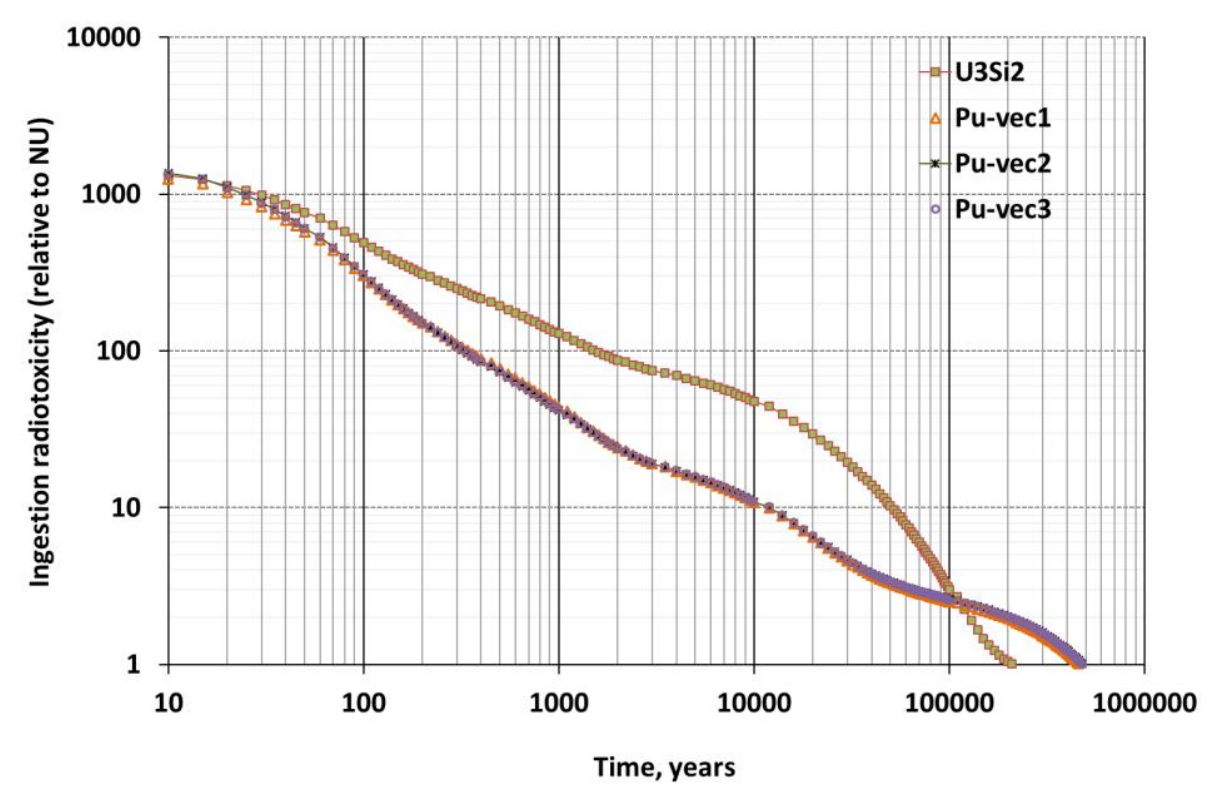

Fig. 18. Relative ingestion radiotoxicity of TOX with different $\mathrm{Pu}$-vectors and $\mathrm{U}_{3} \mathrm{Si}_{2}$ SNF.

\subsection{Decay heat characteristics}

The disposal of SNF and radioactive waste has been extensively studied, almost since the beginning of nuclear power. Geological repositories, such as Yucca Mountain (United States Department of Energy, Office of Civilian Radioactive Waste Management, 2002), have been suggested in the past for the direct disposal of SNF. Such repositories are designed to safely store radioactive materials for extended periods of time while limiting any releases to the environment. In the case of Yucca Mountain, a number of temperature limits that act as constraints on the design are imposed. Meeting these limits can be accomplished by a variety of methods, including controlling the amount of decay heat generated by the waste in any given area of the repository or actively cooling the repository for an extended period of time. Previous research (Wigeland et al., 2006) related to the thermal performance of such repositories investigated chemical separations and transmutation criteria to increase the utilization of space within the repository. That research concluded that the temperature midway between adjacent tunnels (in which the waste is stored) is the controlling safety limit, with the peak temperature occurring between 1500 and 2000 years after waste placement. Due to the extended time-frame for heating this region of the repository and the large heat capacity of the surrounding rock, the temperature peak must be the result 
of the integrated decay heat over time since the placement of the waste rather than the instantaneous value of decay heat at any particular time.

The primary objective of this section is to show how the decay heat characteristics can benefit from incinerating Pu in the TOX core. The results clearly indicate that space utilization in a geological repository would be improved by adopting this approach. However, no quantitative analysis regarding the thermal performance was conducted in the current research.

Fig. 19 shows the decay heat generated by spent $\mathrm{U}_{3} \mathrm{Si}_{2}$ and TOX fuels. It can be observed that the decay heat for all the examined cases drops rapidly after discharge for about the first 200 years. This figure also shows that, as the amount of incinerated $\mathrm{Pu}$ increases, the decay heat in the $50-10^{4}$ years range is considerably lower. Fig. 20 shows the cumulative energy generated by TOX SNF incinerated to different levels relative to the cumulative energy produced by $\mathrm{U}_{3} \mathrm{Si}_{2} \mathrm{SNF}$. The main assumption here was that there is forced convection (Wigeland et al., 2006) during the first 90 years following a cooling time of 10 years.

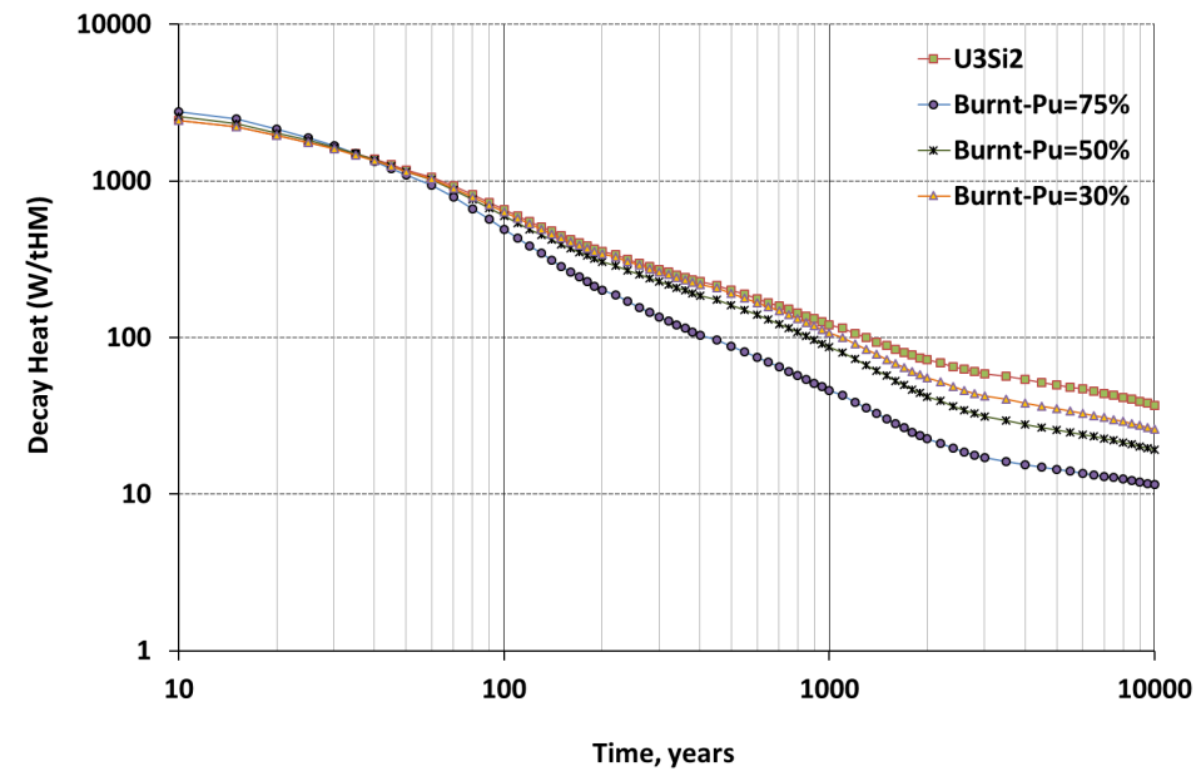

Fig. 19. Decay heat of TOX (incinerated to different levels) and $\mathrm{U}_{3} \mathrm{Si}_{2} \mathrm{SNF}$. 


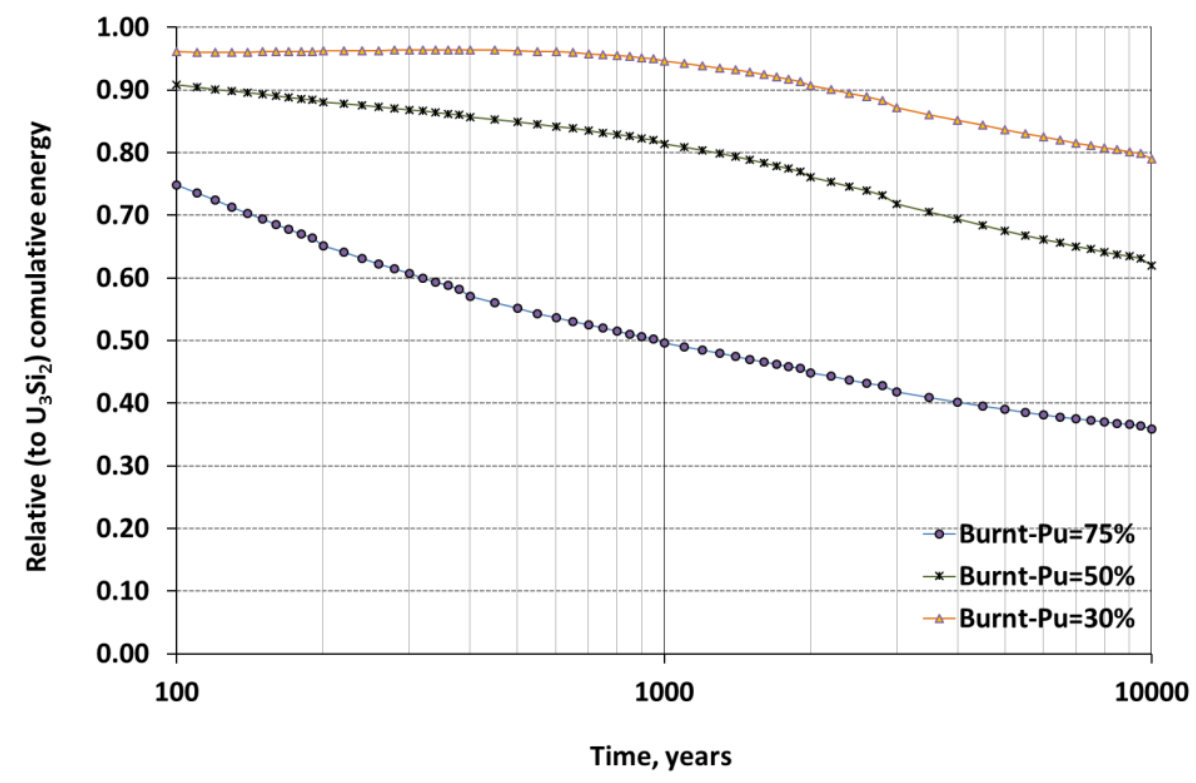

Fig. 20. Cumulative energy of TOX (incinerated to different levels) SNF relative to $\mathrm{U}_{3} \mathrm{Si}_{2} \mathrm{SNF}$.

Fig. 21 and Fig. 22 present the dominant decay heat contributors in the spent fuels of $\mathrm{U}_{3} \mathrm{Si}_{2}$ and $\mathrm{TOX}(75 \%$ incinerated $\mathrm{Pu}$ ) respectively. These figures show that the decay heat is mainly generated by the decay of fission products for the first 60 years, with the contribution dominated by barium $\left({ }^{137 \mathrm{~m}} \mathrm{Ba}\right)$ and yttrium $\left({ }^{39} \mathrm{Y}\right)$ as decay products of cesium $\left({ }^{137} \mathrm{Cs}\right)$ and strontium $\left({ }^{90} \mathrm{Sr}\right)$. After about 60 years, the decay heat is mostly from actinide elements, with the most significant ones being plutonium and americium. Beyond 200 years, the decay heat is generated almost entirely by the plutonium and americium, out to at least $10^{4}$ years. Fig. 21 demonstrates for $\mathrm{U}_{3} \mathrm{Si}_{2} \mathrm{SNF}$ a rather slow decrease of the total decay heat with time, due to the relatively long half-lives of the isotopes ${ }^{241} \mathrm{Am},{ }^{239} \mathrm{Pu}$, and ${ }^{240} \mathrm{Pu}$. In contrast, Fig. 22 presents a sharper decrease in the total decay heat for TOX SNF due to the incineration of Pu isotopes. 


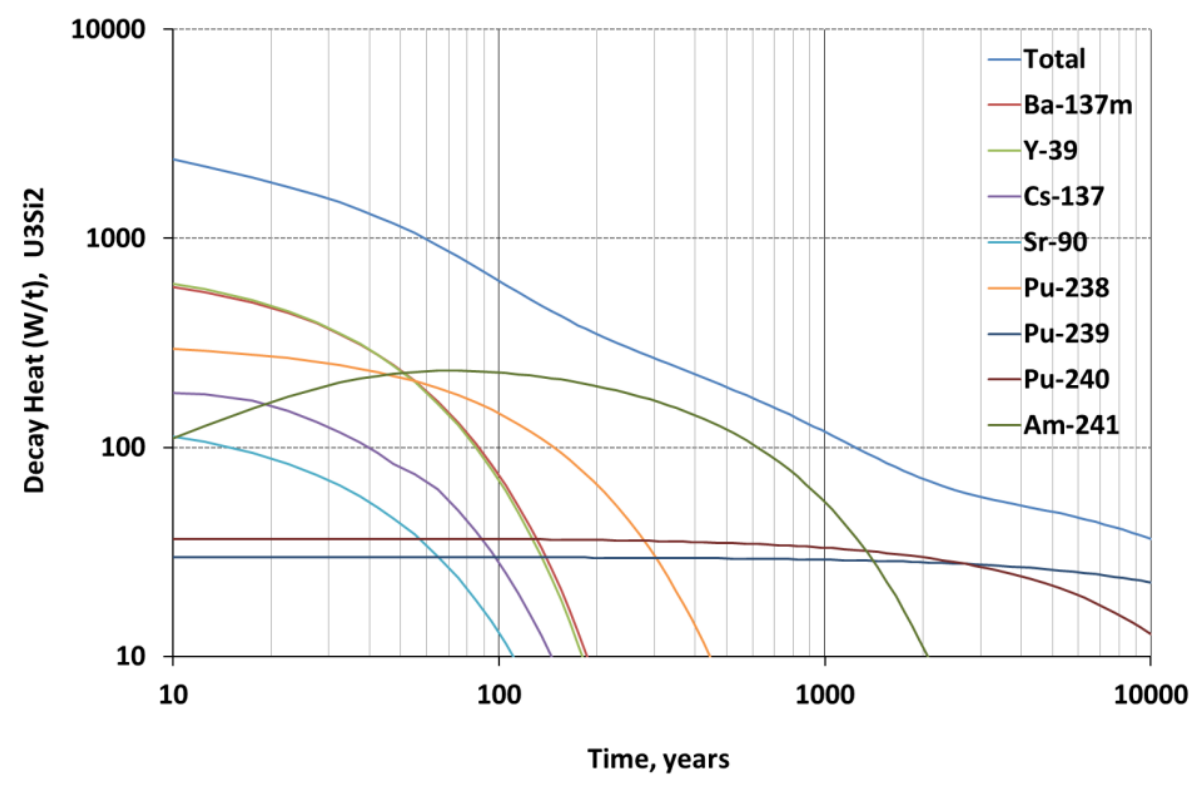

Fig. 21. Dominant decay heat contributors in spent $\mathrm{U}_{3} \mathrm{Si}_{2}$ fuel.

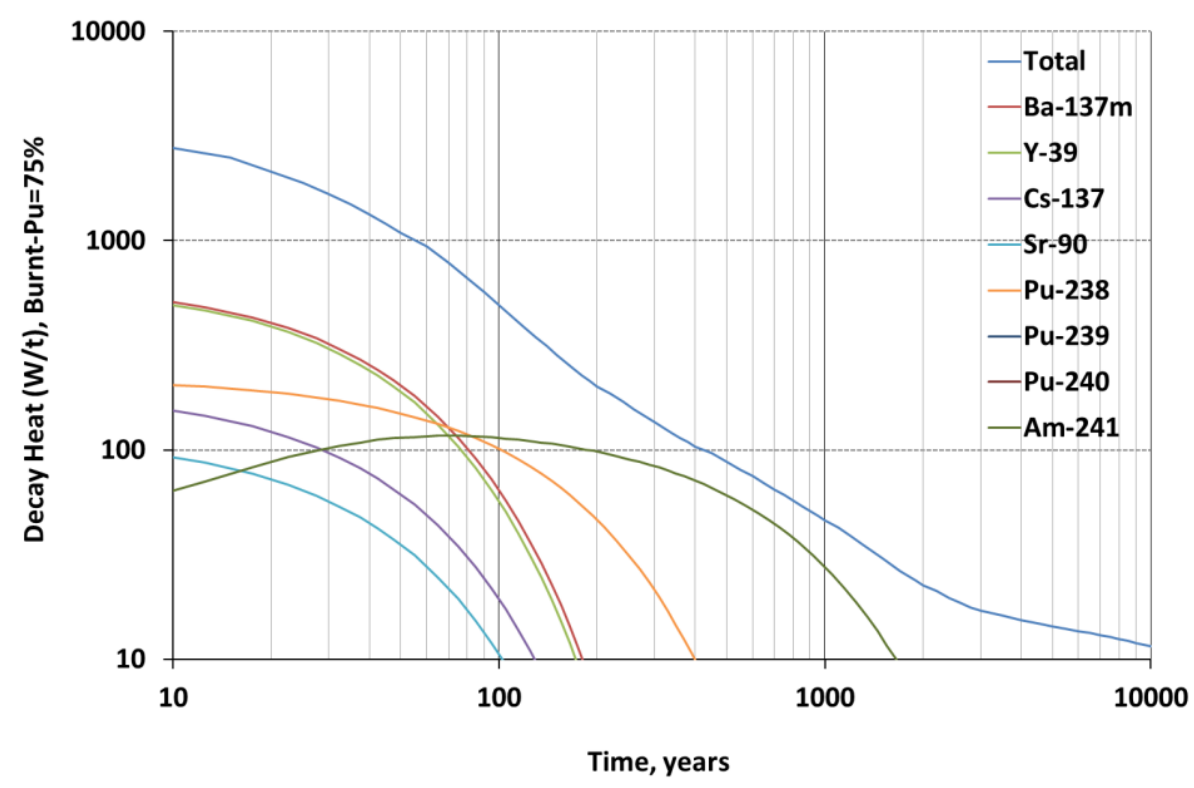

Fig. 22. Dominant decay heat contributors in spent TOX fuel with $75 \% \mathrm{Pu}$ incineration.

Fig. 23 and Fig. 24 show the decay heat of TOX wastes for different $\% \mathrm{PuO}_{2}$ loadings and $\mathrm{Pu}$ vectors respectively (75\% Pu incineration in all cases). The important 
thing to note is that for identical amounts of incinerated plutonium, the variation of decay heat as a function of time is very similar.

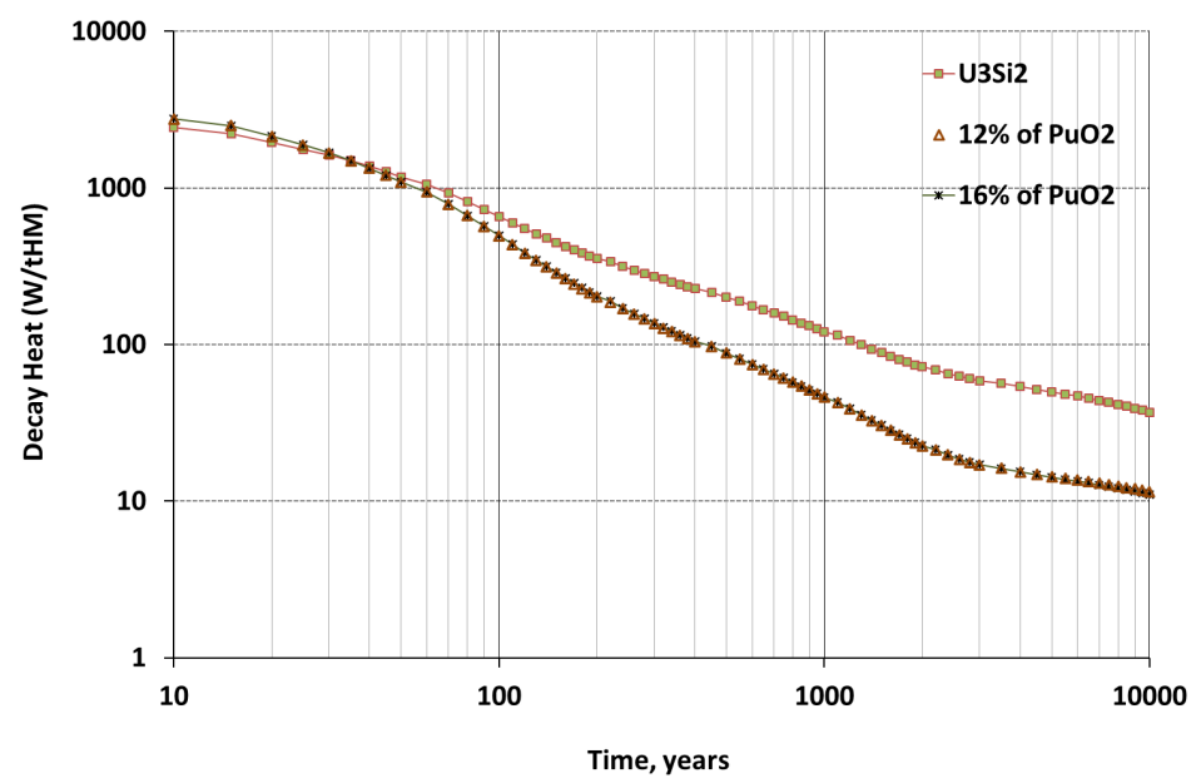

Fig. 23. Decay heat of TOX with different $\mathrm{PuO}_{2}$ volumetric loadings and $\mathrm{U}_{3} \mathrm{Si}_{2} \mathrm{SNF}$.

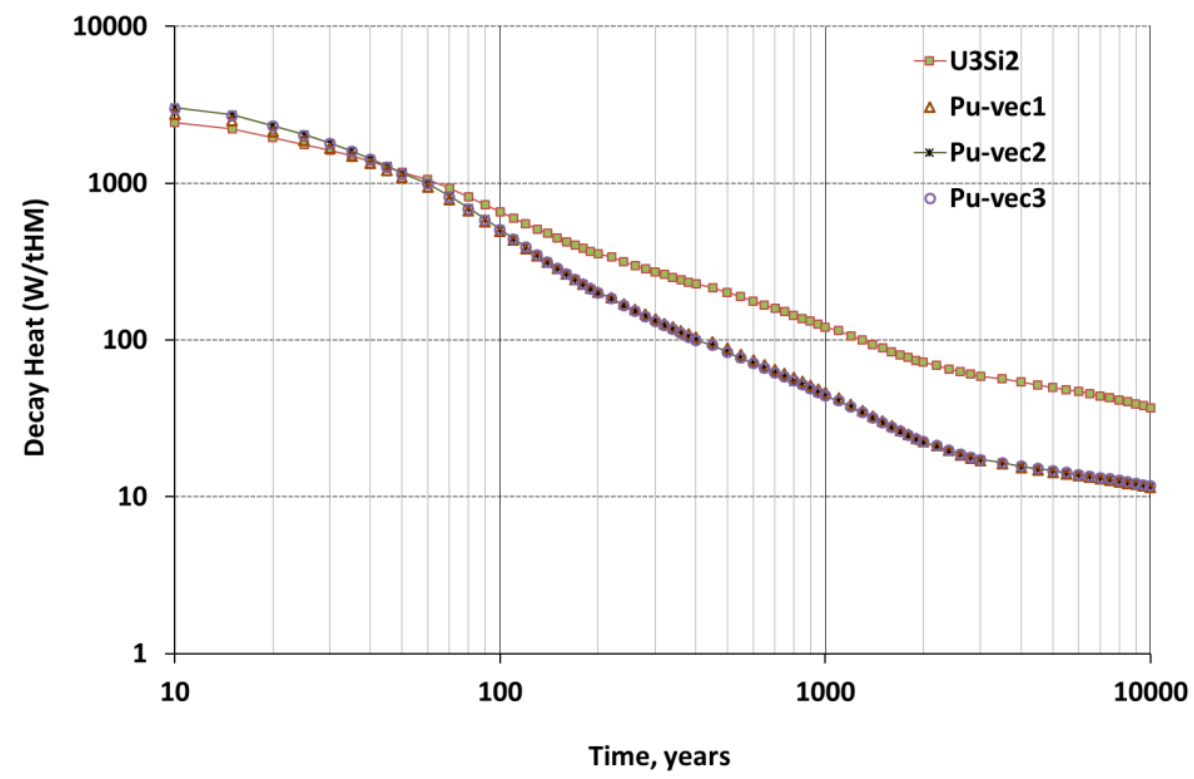

Fig. 24. Decay heat of TOX with different Pu vectors and $\mathrm{U}_{3} \mathrm{Si}_{2} \mathrm{SNF}$. 


\section{Performance summary}

Based on the results presented in the previous sections, several conclusions related to $\mathrm{Pu}$ and TRU incineration efficiency can be drawn:

(1) Switching from advanced $\mathrm{FeCrAl}$ steel to $\mathrm{SiC}$ systematically allows $5 \%$ more $\mathrm{Pu}$ and TRU to be incinerated.

a. For example, Fig. 9 and Fig. 10 show that for $12 \% \mathrm{PuO}_{2}$ and the Pu-2 vector only $70.7 \%$ (45\%) of $\mathrm{Pu}$ (TRU) may be incinerated as opposed to $75.1 \%(51.1 \%)$ when $\mathrm{SiC}$ cladding is used.

(2) The Pu vector has a significant impact $(\sim 12 \%)$ on $\mathrm{Pu}$ and TRU incineration.

a. For example, Fig. 9 and Fig. 10 show that for $12 \% \mathrm{PuO}_{2}$ and $\mathrm{SiC}$ cladding, only $62.1 \%$ (39.4\%) of Pu (TRU) is incinerated when the Pu2 vector is used as opposed to $75.1 \%(51.1 \%)$ with the $\mathrm{Pu}-1$ vector.

(3) Increasing the $\mathrm{PuO}_{2}$ volumetric fraction may or may not enhance the incineration performance.

a. In general, increasing the $\mathrm{Pu}$ volume fraction in the mixture improves the incineration performance up to a certain point, after which the performance is degraded. This happens since a smaller fraction of the fuel is thorium which then leads to less ${ }^{233} \mathrm{U}$ production. Different designs are characterized by different optimum points.

b. In the $\mathrm{FeCrAl}$ case with the $\mathrm{Pu}-2$ vector, for example, increasing the $\mathrm{PuO}_{2}$ loading from $12 \%$ to $16 \%$ also increases $\mathrm{Pu}$ incineration from $57.2 \%$ to $63.7 \%$. However, in the $\mathrm{SiC}$ case with the $\mathrm{Pu}-1$ vector, for the same change in $\mathrm{PuO}_{2}$ loading, $\mathrm{Pu}$ incineration is decreased from $75.2 \%$ to $73.2 \%$.

(4) Increasing the moderator-to-fuel volume fraction reduces the overall performance.

a. A slightly lower Pu incineration was observed. Moreover, the increased fuel power density considerably raises the fuel centerline temperature.

The $\mathrm{Pu}$ and TRU incineration efficiencies for the most favorable TOX cores are reported in Table 6. It must be noted that ${ }^{233} \mathrm{U}$ and ${ }^{233} \mathrm{~Pa}$ were included in the TRU 
inventory in this table. It is believed that these cases are close to optimized since they achieve high $\mathrm{Pu}$ and TRU incineration rates together with reasonable burnup values.

Table 6: Performance summary for $12 \% \mathrm{PuO}_{2}, \mathrm{Pu}-1$ and $\mathrm{H} / \mathrm{HM}-1$.

\begin{tabular}{|l|c|c|}
\hline Cladding & $\mathrm{SiC}$ & FeCrAl \\
\hline Pu burnt (\%) & 75.2 & 70.7 \\
\hline TRU burnt (\%) & 51.1 & 45.0 \\
\hline Discharge burnup (MWd/kg) & 115.7 & 108.9 \\
\hline Cycle length (days) & 375.6 & 350.1 \\
\hline
\end{tabular}

\section{Summary and conclusions}

The original $\mathrm{Pu}$-Th fuel cycle developed for the $\mathrm{I}^{2} \mathrm{~S}-\mathrm{LWR}$ was designed (Kotlyar et al., 2017) to achieve extended fuel burnups (100 MWd/kg), compared to current practice in PWRs $\left(<60 \mathrm{MWd} / \mathrm{kg}\right.$ ), and thus lower Pu residual fractions. The new $\mathrm{I}^{2} \mathrm{~S}-$ LWR cladding materials are suitable for the goal of achieving high burnups. That study indicated that the $\mathrm{Pu}-\mathrm{Th}$ fuel cycle can considerably reduce the $\mathrm{Pu}$ requirements for a fixed energy production and reduce the volume of high-level waste when compared with the MOX fuel cycle.

The analyses were then expanded to consider various multi-batch refuelling strategies, i.e. 3-, 5- and 7.56-batch schemes. For each, the Simulated Annealing optimization technique was used to obtain optimal core configurations for which the cycle length is maximized. The SA method also maintained the cycle total power peaking constraint within acceptable limits. The results demonstrated that increasing the number of batches extends the discharge burnup and hence reduces initial $\mathrm{Pu}$ requirements. In addition, higher discharge burnups result in deeper $\mathrm{Pu}$ and TRU incineration. The optimized LP identified by the SA method showed that up to $62 \%$ and $41 \%$ of $\mathrm{Pu}$ and TRU can be incinerated respectively. The design with the most favourable performance had $16 \% \mathrm{PuO}_{2}$ loading (in the TOX mixture), advanced FeCrAl steel cladding, a fixed $\mathrm{Pu}$ vector and 7.56-batch fuel management. 
In the current research, loading pattern SA optimization was performed for multiple designs that were shown to improve the performance of the TOX cycle. These designs used a 7.56-batch scheme (previously identified as the most favourable), various cladding materials, $\mathrm{Pu}$ isotopic vectors, volumetric fractions of loaded $\mathrm{PuO}_{2}$ and $\mathrm{H} / \mathrm{HM}$ ratios. The results indicate that considerable improvements in the $\mathrm{Pu}$ incineration (with up to $75.2 \%$ of $\mathrm{Pu}$ burnt) could be achieved. This optimized performance is obtained by adopting $\mathrm{SiC}$ cladding and a $\mathrm{Pu}$ vector $(\mathrm{Pu}-1)$ with a high fraction of fissile isotopes.

According to IAEA reports (INFCIRC/549, 1998), the largest plutonium stockpile is in the UK and estimated to be around 112 tonnes. Moreover, the quality of the $\mathrm{Pu}$ vectors within this stockpile is very diverse since it originated from reactor cores with different spectra and irradiated to different burnup levels. Therefore, one could speculate that favourable $\mathrm{Pu}$ vectors could be created by appropriate mixing of these different $\mathrm{Pu}$ isotopic compositions.

To conclude, the current study investigated the feasibility of enhancing the performance of the $\mathrm{Pu}$-Th fuel cycle for the $\mathrm{I}^{2} \mathrm{~S}-\mathrm{LWR}$ by selecting the most favourable set of fuel-cladding combinations with respect to the highest incineration of $\mathrm{Pu}$. Achieving deeper incinerations allows the decay heat of the spent nuclear fuel to be reduced significantly, which will allow the disposition of more waste in a given repository.

\section{Acknowledgements}

This research was sponsored by the UK Engineering and Physical Sciences Research Council (EPSRC) under grant EP/K033611/1.

\section{Data availability statement}

To the best of the authors' knowledge, this paper and references herein contain all the data needed to reproduce and validate the results presented. 


\section{References}

Bomboni, E., Cerullo, N., Fridman, E., Lomonaco, G., Shwageraus, E., 2010. Comparison among MCNP-based depletion codes applied to burnup calculations of pebble-bed HTR lattices. Nucl. Eng. Des. 240 (4), 918-924.

Fridman, E., Shwageraus, E., Galperin, A., 2008. Efficient generation of one-group cross sections for coupled Monte Carlo depletion calculations. Nucl. Sci. Eng. 159, $37-$ 47.

IAEA, 1998. Communication received from certain member states concerning their policies regarding the management of plutonium. Information Circular INFCIRC/549. International Atomic Energy Agency, Vienna, Austria.

IAEA, 2003. Status and advances in MOX fuel technology. Technical Report STI/DOC/010/415. International Atomic Energy Agency, Vienna, Austria.

ICRP, 1995. Age-dependent Doses to the Members of the Public from Intake of Radionuclides - Part 5 Compilation of Ingestion and Inhalation Coefficients. ICRP Publication 72. Ann. ICRP 26 (1).

Kirkpatrick, S., Gelatt, C., Vecchi, M., 1983. Optimization by simulated annealing. Science 220, 671-680.

Kotlyar, D., Shaposhnik, Y., Fridman, E., Shwageraus, E., 2011. Coupled neutronic thermo-hydraulic analysis of full PWR core with Monte-Carlo based BGCore system. Nucl. Eng. Des. 241 (9), 3777-3786.

Kotlyar, D., Parks, G., Shwageraus, E., 2017. Thorium-based plutonium incineration in the $\mathrm{I}^{2} \mathrm{~S}-\mathrm{LWR}$. Ann. Nucl. Energy, in press.

Kotlyar, D., Parks, G., 2016. Enhancing plutonium incineration in the thorium-based $\mathrm{I}^{2} \mathrm{~S}-\mathrm{LWR}$ design with loading pattern optimization. Ann. Nucl. Energy 96, 401-411. 
Lindley, B.A., Kotlyar, D., Parks, G.T., Lillington, J.N., Petrovic, B., 2016. Reactor physics modelling of accident tolerant fuel for LWRs using ANSWERS codes. EPJ Nucl. Sci. Technol. 2, 1-9.

Metropolis, N., Ulam, S., 1949. The Monte Carlo method. J. Am. Statist. Assoc. 44, $335-341$.

Morrison, A., 2003. PANTHER User Guide. Technical Report. British Energy, Barnwood, United Kingdom.

Newton, T., Hosking, G., Hutton, L., Powney, D., Turland, B., Shuttleworth, E., 2008.

Developments within WIMS10. In: Proc. PHYSOR, Interlaken, Switzerland.

Petrovic, B., 2014. Integral inherently safe light water reactors $\left(I^{2} S-L W R\right)$ concept: extending SMR safety features to large power output. In: Proc. ICAPP 2014, Charlotte, North Carolina, USA.

Salazar, D., Franceschini, F., 2014. I²S-LWR equilibrium cycle core analysis. In: Proc. PHYSOR 2014, Kyoto, Japan.

Salazar, D., Franceschini, F., Ferroni P., Petrovic B., 2015. I²S-LWR fuel management options for an 18-month cycle length. In: Proc. ANFM 2015, South Carolina, USA.

Shwageraus, E., Hejzlar, P., Kazimi, M.S., 2004. Use of thorium for transmutation of plutonium and minor actinides in PWRs. Nucl. Technol. 147, 53-67.

Shwageraus, E., Hejzlar, P., 2009. Decay heat in fast reactors with transuranic fuels. Nucl. Eng. Des. 239 (12), 2646-2653.

Terrani, K., Keiser, J., Brady, M., Cheng, T., Silva, G., Pint, B., Snead, L., 2012. High temperature oxidation of silicon carbide and advanced iron-based alloys in steamhydrogen environments. In: Proc. TopFuel 2012, Manchester, United Kingdom. 
United States Department of Energy, Office of Civilian Radioactive Waste Management, 2002. Yucca Mountain Science and Engineering Report, DOE/RW-5391, Rev. 1.

Wigeland, R.A., Bauer, T.H., Fanning, T.H., Morris, E.E., 2006. Separations and transmutation criteria to improve utilization of a geological repository. Nucl. Technol. $154,95-106$. 